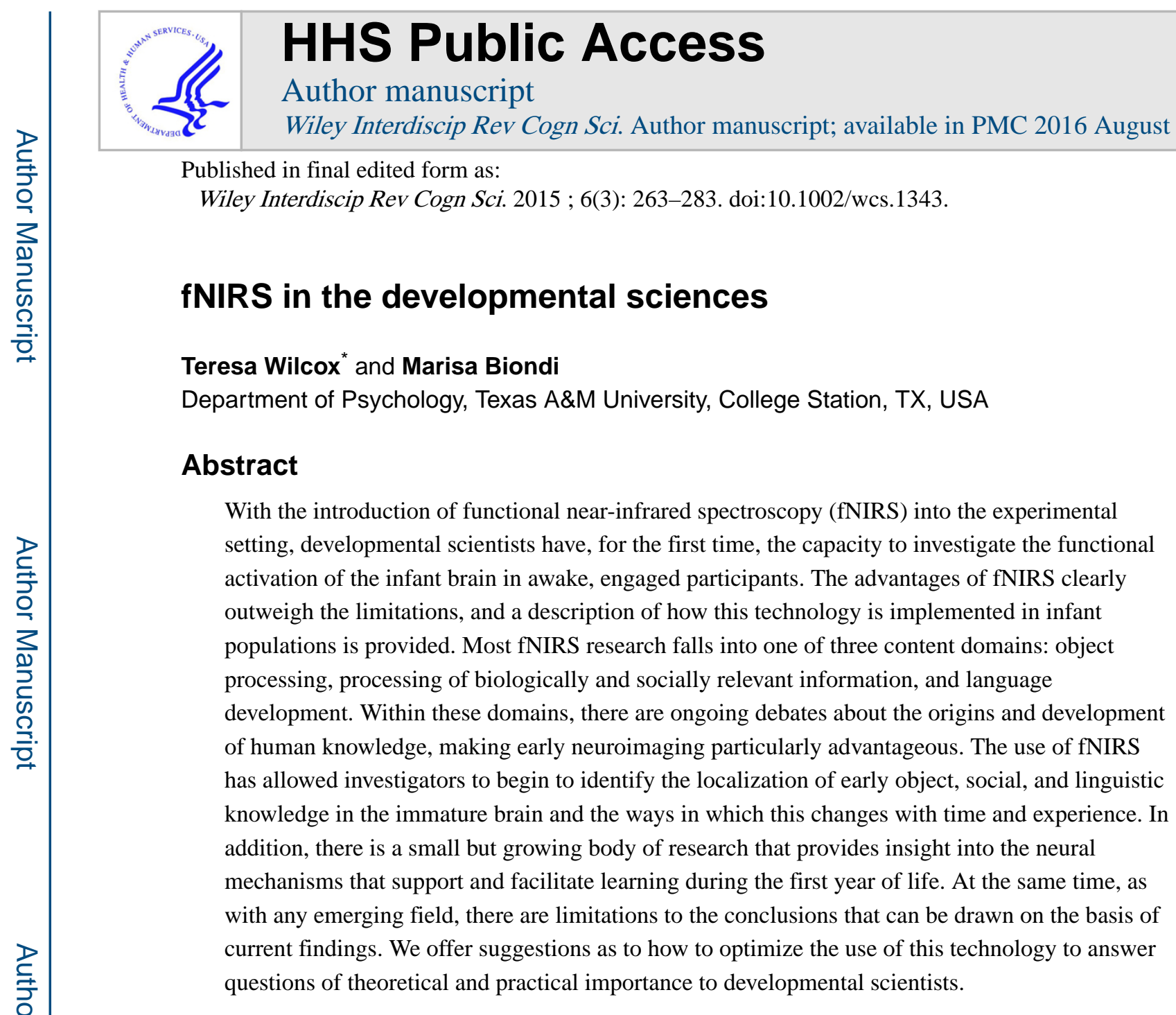

\title{
INTRODUCTION
}

Over the last 45 years, we have made tremendous progress in our understanding of the developing human brain. Advancements in behavioral testing techniques have allowed us to draw strong inferences about what infants are perceiving, thinking, and feeling and how this changes with time and experience. At the same time, the neural underpinnings of these developing capacities have remained elusive, in large part because of the limited methods available to study brain-behavior relations in human infants. Introduction of the functional near-infrared spectroscopy (fNIRS) as a viable tool for measuring brain activation, ${ }^{1}$ and then application of this technique to infants, ${ }^{2}$ has radically changed the landscape, offering developmental scientists the opportunity to investigate the functional organization of the cortical systems that underlie the emerging capacities identified in behavioral studies.

There has been some discussion about the extent to which neuroimaging data can contribute to psychological theory ${ }^{3-5}$ and, more specifically, to our understanding of the origins and development of human knowledge. ${ }^{6,7}$ We argue, along with others, that the potential

\footnotetext{
"Correspondence to: twilcox@tamu.edu.

Conflict of interest: The authors have declared no conflicts of interest for this article.
} 
contributions are significant. One advantage of neuroimaging techniques, such as fNIRS, is that they allow us to identify the localization (the extent to which a response is limited to a cortical area) and the specialization (the extent to which a cortical area responds selectively) of neural responses. With a good experimental design, including appropriate control conditions, we can identify the cortical structures, or group of cortical structures, that mediate select processes. This information can inform developmental theory in a number of ways. For example, from these data, we can gain insight into the functional organization of the immature brain (prior to extensive experience) and begin to draw inferences about the conditions under which domain-specific and/or domain-general mechanisms guide learning. This is just a starting point, however. The goal of developmental research is to understand how knowledge and representational capacities change over time, and how these changes come about. In order to answer these questions, we must study different age groups, using both cross-sectional and longitudinal designs. Although there are a number of possible approaches for identifying the mechanisms of change, two that have proven fruitful include assessing the effect of differences in early experience ${ }^{8,9}$ and of specific training procedures ${ }^{10,11}$ on brain and behavior.

Another way in which neuroimaging data can make important contributions to the developmental sciences is by providing insight into infants' perception of and thinking about their world that may not be otherwise evident. Because infants have a limited behavioral repertoire, sometimes it is difficult to ascertain, from behavioral data alone, the engagement of distinct perceptual, cognition, or social processes. Assessing cortical responses to different stimuli can allow us to draw conclusions about whether two stimuli are processed in different, or similar, ways. To illustrate, looking at time measures may show similar visual responses to faces that display happy and neutral expressions. However, neuroimaging data may reveal different cortical responses to those stimuli, suggesting that they were perceived or processed in a different way. Alternatively, patterns of neural activation may suggest that two different stimuli engage common or shared processes. Of course, care must be taken in data interpretation. Since fNIRS measures information from only the cortical areas, we do not have information about activation in the subcortical areas that might be part of a processing circuit. In addition, the extent to which reverse inferences (e.g., inferring from activation patterns that specific processes were engaged) should be used in the interpretation of neuroimaging data is a point of debate. ${ }^{3-5}$

We have not only outlined, above, the strength of neuroimaging techniques, but also acknowledged that there are valid concerns about the extent to which fNIRS has been used in a way that allows researchers to draw strong conclusions. ${ }^{6,7}$ Some concerns have to do with the experimental approach. For example, there are a limited number of studies that are motivated by developmental hypotheses, assess learning mechanisms, and/or are designed in a way to inform theory (we return to this in the conclusion). Perhaps one of the most frequently observed pitfalls is overinterpretation of the data. For example, finding activation in inferior frontal cortex to a select stimulus does not reveal anything about localization of the response unless other cortical areas are not assessed. Likewise, finding activation in the inferior frontal cortex to a select stimulus does not reveal anything about cortical specialization unless hemodynamic response to other experimental stimuli, and control stimuli, is measured. Other concerns have to do with methodological or technical issues. For 
example, failure to standardize probe placement makes it (even more) difficult to draw conclusions about the cortical structures from which one is measuring; lack of standardized approaches to data processing and data analysis limits comparison of findings across labs (we will also return to this in the conclusion); and contamination of the optical signal due to changes in blood flow in the skin has yet to be fully addressed.

Despite these concerns, fNIRS research has made important and unique contributions to the developmental sciences. This review is organized to first provide a basic overview of fNIRS and how it is implemented with infants. We then review some of the main findings that have emerged through the use of this technology and that have made unique contributions to the field. Finally, we discuss the current directions and offer suggestions as to how we can optimize the use of this technology.

\section{FUNCTIONAL NEAR-INFRARED SPECTROSCOPY (fNIRS)}

In fNIRS, near-infrared light is projected through the scalp and the skull into the brain and the intensity of the light that is diffusely refracted is recorded. Neural activation in response to a stimulus results in increased blood flow to the area activated. Change in blood flow leads to an increase in blood volume and can be assessed by measuring the local concentrations of oxyhemoglobin ( $\mathrm{HbO})$, deoxyhemoglobin ( $\mathrm{HbR}$ ), or the summed total $(\mathrm{HbT})$. Typically, during cortical activation, local concentrations of $\mathrm{HbO}$ increase and those of HbR decrease. ${ }^{12-15}$ To capitalize on the changes in local concentrations of $\mathrm{HbO}$ and $\mathrm{HbR}$, the low tissue absorption of near-infrared light between 650 and $950 \mathrm{~nm}$ is utilized. ${ }^{16-18}$ Light intensity modulation during stimulus presentation is compared with that during a baseline event in which no stimulus or a control stimulus is presented. Change relative to the baseline provides information about the hemodynamic response to brain activation. Evidence that there is a linear relationship between hemodynamics and neural activity ${ }^{19}$ and that fNIRS produces results consistent with other imaging techniques (i.e., fMRI and PET) used simultaneously ${ }^{20-23}$ provides converging evidence that fNIRS offers a reliable measure of brain function.

\section{Advantages}

The use of fNIRS has several distinct advantages over fMRI. First, fNIRS has much better temporal resolution: brain signals can be routinely observed with a temporal sampling resolution of 0.01 second, which is faster than that typically observed with fMRI. ${ }^{1,24,25}$ While the hemodynamic response to brain activation occurs on a 1-2 seconds time scale, the better temporal resolution offered by fNIRS can, for instance, enable better distinction of signal contamination arising from systemic physiological signals and motion artifacts, better resolution of the hemodynamic onset, and, potentially, allow for direct measures of fast neuronal signals. A second advantage is that fNIRS can be implemented with awake, engaged infants. Typically, fMRI studies are conducted with sleeping or sedated infants to avoid motion artifacts, which render data unusable. This limits the types of experiments that can be conducted. In addition, caution is warranted in the generalization of neural responses recorded in sleep states to wake states. ${ }^{26}$ Swaddling can permit data collection in awake infants, but this approach is challenging to implement. A third advantage of fNIRS as 
compared with fMRI is that fNIRS is noninvasive and nonionizing. Hence, it is safe to use with infants repeatedly and for extended periods of time. Finally, fNIRS technology is relatively inexpensive, portable, and, with the appropriate training, straightforward to use. The main advantage of fNIRS over EEG/ERP is the localization of responses. In fNIRS, the effects are localized within 1-2 $\mathrm{cm}$ of the area activated, allowing for more accurate identification of the areas from which cortical responses were obtained than electrophysiological techniques. As fNIRS technology develops, and as we increase the number of emitters and detectors that are used, functional brain mapping becomes possible.

\section{Challenges and Limitations}

At the same time, there are a number of potential difficulties with using fNIRS. The first has to do with the neural structures that can be targeted for investigation. Near-infrared light diffuses rapidly while entering neural tissue, rendering fNIRS unsuitable for investigation of neural activation in structures deeper than about $1 \mathrm{~cm}$ below the surface of the brain. Second, fNIRS measures neural activation from the head surface without anatomical information about the brain area being studied. Although there are a number of ways to resolve this problem, ${ }^{27}$ one approach often used with infants is to position probes on the basis of the International 10-20 system for EEG recording. In adults, 10-20 coordinates have been mapped onto underlying cortical structures. ${ }^{28}$ Although we cannot assume that infant and adult craniocerebral correspondences are identical, this is a reliable method for probe placement and when infant craniocerebral correspondences do become available, recorded head measurements can be used to conduct more detailed analysis of activation patterns with previously collected data sets. Third, although spatial resolution of fNIRS is better than that of ERP/EEG, it is inferior to that of fMRI. This can make it difficult to distinguish neural responses from discrete, adjacent cortical areas.

In summary, the advantages of fNIRS lay at the intersection of the disadvantages of fMRI and EEG/ERP. fNIRS has better temporal resolution, is easier, and more cost effective to implement than fMRI (although spatial resolution is more limited). In comparison, fNIRS has better spatial resolution than EEG/ERP (but temporal resolution is more limited). The greatest benefit will be realized through the use of all three (and related) techniques to address questions that cannot be adequately answered through a single method.

\section{Instrumentation}

There are a number of good reviews on instrumentation and, for the purpose of this review, we will not go into great detail here. ${ }^{29-32}$ Briefly, there are three types of fNIRS instruments: continuous wave, frequency domain, and time domain. Continuous wave $(\mathrm{CW})$ devices use sources that emit light at a constant frequency, and the amplitude and changes in the intensity of the light are recorded. Although the wavelengths that investigators use vary, there is evidence that paired wavelengths of approximately $690 \mathrm{~nm}$ and $830 \mathrm{~nm}$ are optimal for measuring deoxyhemoglobin and oxyhemoglobin, respectively. ${ }^{7-9}$ Typically, two wavelengths are used, but more are possible. Measurement of light attenuation through cortical tissue is used as an indicator of neural activation. CW devices are relatively inexpensive to build, technologically simple, and easy to use. Hence, infant researchers use $\mathrm{CW}$ devices almost exclusively. Frequency domain (FD) instruments emit light at different 
frequencies, and measurement of the attenuation and phase delay of the light is used to quantify neural activation. Time domain (TD) devices emit short pulses of light, around the order of picoseconds, and changes in the shape of the signal as it moves through the neural tissue is used as a measure of hemodynamic responses. TD and FD systems are more expensive to build and technologically more complicated, and hence, infrequently used with infants in the experimental setting. However, these techniques do allow for a greater depth penetration through the neural tissue and for the measurement of absolute concentrations of oxygenated and deoxygenated hemoglobin, which cannot be accomplished with $\mathrm{CW}$ devices.

\section{Experimental Design}

Although a number of designs can be used in fNIRS research, in the developmental sciences, almost all studies have used a block design (for exceptions, see Refs 33-35). In a block design, infants are presented with a test stimulus for a set duration (typically 5-30 seconds) alternating with a baseline event. The test stimulus needs to be of sufficient duration to observe the onset of a hemodynamic response, which is about 1-2 seconds, but not so long that infants become inattentive and restless during the trial, which can lead to increased prevalence of motion artifacts. Hemodynamic responses, under ideal experimental conditions, should be evident in a single trial but because the signal-to-noise ratio is often compromised for any number of reasons (e.g., instrument noise, physiological responses, poor optode-scalp coupling) or motion artifacts are obtained, a greater number of trials are typically needed for data analysis. At the same time, trial repetition can lead to neural adaptation effects, ${ }^{36}$ which have been observed in infant hemodynamic responses. ${ }^{37}$ The number of trials one uses depends, in part, on the trial length. The longer each trial, the fewer trials infants will tolerate, and the reverse. We have found that with trial lengths of 20 seconds, infants can successfully complete 6-10 trials, which is consistent with that reported by other researchers. ${ }^{38}$ In a more recent work, we have found that using a control stimulus, rather than a silent pause (see below), during the baseline interval increases the number of trials that the infants will tolerate.

Because hemodynamic responses obtained to a test event are assessed relative to a baseline event, the nature of the baseline event is critical to data interpretation. Some researchers have used 'no stimuli' as a baseline event. ${ }^{39,40}$ The advantage of a no-stimuli baseline is that one can assess hemodynamic responses to experimental and control events relative to no event. The disadvantage is that we have little information about the processes in which infants engage in the absence of a visual or auditory event. An alternative approach is to present a control event during the baseline interval and interpret a hemodynamic change relative to the control event. ${ }^{37,41}$ The advantage of this approach is that patterns of activation relative to the control event are directly assessed. The disadvantage is that one loses information about patterns of activation that are common to the two events. In addition, care must be taken to ensure that the experimental and baseline (control) events vary only on the dimension(s) of interest. If not, it is difficult to interpret the basis for the hemodynamic response observed.

Wiley Interdiscip Rev Cogn Sci. Author manuscript; available in PMC 2016 August 10. 
One must also consider the duration of the baseline interval, which must be sufficient for the hemodynamic response to return to its original state. Although this depends on the test stimuli used, most infant researchers have found 10 seconds to be sufficient. If participants are presented with a large number of trials each followed by a baseline interval of the same duration, anticipatory responses can occur. ${ }^{42}$ This can be handled by using a jittered design, where the baseline interval is varied so that the onset of the test stimulus is difficult to predict.

Finally, decisions made about the experimental design influence exclusion rates. The less interesting the infants find the stimuli, the longer the trial, and the more trials infants are presented, the less likely infants are to successfully complete the requisite number of trials to be included in data analysis. Data exclusion can occur for a number of reasons: the infant was asleep, fussy, crying; the infant stopped attending to the stimuli; or the optical data collected were of poor quality (e.g., poor optode-scalp coupling, motion artifacts). The comfort of the headgear and the ease of headgear placement on the infant's head also affect exclusion rates.

\section{Data Processing and Analysis}

While there are currently no standardized procedures for processing fNIRS data, most investigators have some method for removing the physiological noise (low frequency oscillations) and the motion artifacts (abrupt intense changes) from the optical signal. $31,33,43$ In addition, channels and time periods in which the optical signal is of poor quality are also identified and removed. Many researchers also eliminate trials on the basis of behavioral criteria (e.g., drowsiness, crying, failure to attend), although this can be done after data processing. Once the optical signal has been processed, the data are converted from optical density units to local concentrations of $\mathrm{HbO}$ and $\mathrm{HbR}$ using the modified Beer-Lambert Law, ${ }^{44}$ and a time epoch immediately prior to stimulus onset is set to 0 for each trial. Changes in the optical signal relative to 0 are calculated on a trial-to-trial basis by computing the mean hemodynamic response (averaged over a predetermined time epoch) or the peak hemodynamic response (within a predetermined time epoch) relative to baseline 0 , for each channel separately. Trials can be averaged to compute means, for each channel and condition. Figure 1 illustrates a typical hemodynamic response function. Finally, although exclusion rates vary, on an average, about $40 \%$ of the infants tested are excluded from data analysis because of the failure to meet processing criteria. ${ }^{38}$ As implementation and data processing techniques improve, we anticipate that these percentages will decrease.

The most common data analysis approach has been to (1) compare responses obtained at individual channels to 0 , for each condition separately, to identify the channels at which a significant hemodynamic response occurred and (2) compare responses obtained at individual channels across conditions. However, if a large number of channels are assessed, correction procedures should be implemented, which in itself can be problematic. Alternative approaches include (1) selecting channels or groups of channels (i.e., cortical areas) of interest on the basis of theoretically based predictions and/or previously published results or (2) employing statistical techniques for identifying individual or groups of 
channels that are commonly activated during stimulus events. A current review of statistical analysis techniques is available. ${ }^{45}$

\section{REVIEW OF MAIN FINDINGS}

One of the primary advantages of fNIRS is that it allows us to identify cortical responses to a wide range of stimuli in awake, processing infants prior to extensive social, educational, and environmental influences. We suggested earlier that given a good experimental design, fNIRS data can inform long-standing questions about the origins and development of human knowledge. Our review focuses on studies that have, to some extent, made such contributions. Most of this research can be broadly grouped into three content areas: object processing, socioemotional processing, and language development. Because of space limitations, single studies outside of these areas will not be reviewed. Unless otherwise noted, the terms 'hemodynamic response' and 'neural activation' refer to an observed increase in $\mathrm{HbO}$ or $\mathrm{HbT}$.

\section{Object Processing}

A great deal is known about the functional organization of object processing networks in the adult brain, and these findings have made important contributions to our understanding of the complex set of perceptual and cognitive processes involved in object recognition, identification, and categorization. ${ }^{46-53}$ In contrast, relatively little is known about object processing networks in the infant brain and how the development of these networks is related to changes in behavior. Current research on infants' reasoning about physical objects suggests that some object processing networks might change substantially over the first year, whereas other networks might remain more stable. ${ }^{54}$ To begin to fill this gap in knowledge, Wilcox and colleagues have investigated the neural basis of infants' emerging capacity to track the identity of objects using featural and spatiotemporal information.

Featural Information-The purpose of these studies was to identify the cortical areas that mediate individuation-by-feature, a capacity that emerges gradually over the first year. In feature-based studies, ${ }^{55,56}$ infants aged between 3 and 12 months were shown events in which the objects that emerged successively from behind an occluding screen differed in shape, color, or were identical in appearance (Figure 2). A headgear targeting four cortical areas was placed on the infant's head (Figure 3). Headgear configuration and placement was designed to map onto the International 10-20 system (Figure 4). During baseline, no visual or auditory stimuli were presented. As expected, the occipital cortex was activated in responses to all the events, regardless of the infants' age or the event condition. ${ }^{40,57,58}$ Of greater interest are the patterns of activation observed in the anterior and posterior temporal cortex (ventral areas) and posterior parietal cortex (dorsal area).

Three main findings emerged. First, anterior temporal activation was obtained only in response to events in which infants individuate by feature. Infants aged 3-9 months, who use shape but not color information to individuate objects, ${ }^{59}$ showed activation in the anterior temporal cortex when viewing the shape difference but not the color difference event. In contrast, infants aged 11-12 months, who use shape and color information to individuate objects, ${ }^{59,60}$ showed activation in the anterior temporal cortex when viewing the shape 
difference or the color difference event. ${ }^{11,55,56,61}$ The control event, which infants interpret as involving a single object, ${ }^{59}$ did not activate anterior temporal cortex in any age group. Finally, additional studies revealed that select experiences known to prime infants to attend to color information, when presented to 8- to 9-month-old infants prior to the color difference test event, led to individuation-by-color and activation in the anterior temporal cortex. ${ }^{11}$ These results are consistent with adult fMRI data implicating areas in the anterior temporal cortex to be important for mediating higher level object processes, such as object identification and categorization, and demonstrate experience-dependent changes in the infant brain that are directly linked to behavior. ${ }^{47,48,52,62}$ Future work will be geared toward identifying the larger cortical circuit associated with this 'individuation response' and to better understand the nature of the underlying representations. For example, anterior temporal activation may be in response to a specific individual (e.g., that red ball) or to a category of individuals (e.g., red-colored balls).

Second, responses in the posterior temporal cortex were not condition specific. Infants aged 3-7 months showed activation in the posterior temporal areas in response to all three test events, but the magnitude of the response did not vary by event condition. ${ }^{55,56}$ Although the role of the posterior temporal cortex in this experimental context is not entirely clear, one hypothesis is that it mediates processing of objects as whole entities (but not as individuals). Consistent with this hypothesis, other studies have found activation in this area that is (1) specific to objects, and not nonobject visual stimuli such as reversing checkerboard patterns or faces, ${ }^{35,37,63,64}$ but (2) independent of the properties of the objects involved. ${ }^{35,55}$ These characteristics lead us to suspect that this area in the infant serves a function similar to that of lateral occipital complex (LOC), a mid-level object processing area near the occipitaltemporal border, identified in the adult (Figure 5). ${ }^{48,51,52}$ However, responses in the posterior temporal cortex were age specific. Infants aged 11-12 months did not show posterior temporal activation to any of the test events. ${ }^{56}$ This outcome suggests a functional reorganization of the ventral object processing network during the second half of the first year, which might involve a change in the localization of the requisite processes and/or a paring down of the cortical areas involved. Age-related paring down of the object recognition network has been observed in the nonhuman primate. ${ }^{65}$

Third, age-related changes in parietal activation were obtained in response to the shape difference event. ${ }^{56,61}$ Infants aged 6 months and less, but not older infants, showed activation in the posterior parietal cortex during the shape difference event. Parietal activation was not obtained in response to the color difference or control event. Dorsal activation in response to shape differences is an intriguing, but not altogether unexpected, finding. In the adult, shape processing can activate dorsal or ventral areas depending on how shape is processed. ${ }^{66-70}$ On the basis of this and related work, Wilcox and colleagues ${ }^{62}$ hypothesize that the parietal activation obtained in the younger infants reflects (1) a less well-developed visual system with limited visual acuity, leading to greater dependence on motion-carried information to extract object shape; (2) a focus on the affordances of objects when assessing object structure, leading to dependence on dorsal areas for the processing of 'how' information; or (3) attention to shape as a spatial attribute, leading to dependence on dorsal areas for processing of 'where' information. The aim of future research must be to test these hypotheses. 
Spatiotemporal Information-Behavioral studies show that infants as young as 3-4 months interpret a speed discontinuity and a path discontinuity event, but not a control event, such as those displayed in Figure 6, as involving two distinct objects. ${ }^{71-74}$ One study assessed the patterns of neural activation, using the headgear displayed in Figure 3 in infants aged 5-7 months. ${ }^{55}$ Two main findings emerged. First, activation was obtained in the anterior temporal cortex only in response to the speed and path discontinuity event (activation was obtained in the posterior temporal cortex to all three events), providing converging evidence for the conclusion that anterior temporal cortex is critical to the individuation process. Second, activation was obtained in the posterior parietal cortex to the speed discontinuity and path discontinuity but not the control event, most likely in response to the spatiotemporal discontinuities embedded in the occlusion event. A more recent study provides converging evidence for these findings, and also reveals age-related changes in hemodynamic responses to some spatiotemporal discontinuities. ${ }^{61}$

In summary, the studies reviewed in this section show the unique contribution of select ventral and dorsal areas to object identification during the first year. Particularly novel are the studies that demonstrate the importance of experience-dependent processes to infants' learning about objects, which was reflected in both brain and behavioral responses. Further work is needed to provide a more comprehensive picture, using a greater number of channels distributed bilaterally, about the functional organization of early emerging object processing pathways and how this changes with time and experience.

\section{Processing of Biologically and Socially Relevant Information}

There is a large body of behavioral work on infants' perception of and reasoning about biological and social objects. This work has revealed early sensitivity to faces, biological motion, communicative signals, and other types of information that facilitates effective social interaction. ${ }^{75-77}$ These findings have led developmental scientists to (1) question whether the human brain is functionally organized, from the early days of life, to make sense of biologically and socially relevant information and (2) form hypotheses about the types of experience that might facilitate the development of more sophisticated social understanding. In response, there is a growing body of fNIRS research on the neural underpinnings of infants' early emerging understanding of biological and social objects. These studies can be grouped into three main areas: face processing, processing of human motion, and processing of communicative intent.

Face Processing-From the early months of life, infants prefer upright faces to inverted, scrambled, and other nonface stimuli and are adept at recognizing and discriminating between familiar and unfamiliar faces. ${ }^{78-80}$ In the adult, there is a distributed network of areas important for the recognition and identification of face stimuli, including the fusiform face area (FFA), the posterior part of the superior temporal sulcus (STS), and the occipital face area (OFA) ${ }^{78,49}$ Face processing is typically right hemisphere dominant. To assess the extent to which cortical areas are specialized for face processing in the infant, Otsuka and colleagues ${ }^{81}$ presented 5- to 8-month-old infants with photos of faces that were either upright or inverted (baseline stimuli were photos of vegetables) and measured from an array of optodes centered bilaterally at T3 and T4 (Figure 7), which lies over the anterior temporal 
areas of the cortex (see Figure 4). Activation was obtained in the right temporal cortex when viewing upright but not inverted faces (relative to baseline stimuli). Right hemisphere dominance has also been obtained for unscrambled as compared to scrambled faces and for face-like point light displays ${ }^{63,82}$ At the same time, there are developmental changes in the cortical responses to faces. For example, right temporal activation is obtained to frontal views of faces at 5 months, but it is not until 8 months that the infants show right temporal activation to profile views. ${ }^{83}$ These results are consistent with behavioral data reporting that infants become more adept at recognizing faces from different angles between 6 and 7 months. ${ }^{84-86}$

There are situations in which activation patterns are not right dominant. For example, 7- to 8-month-old infants show bilateral temporal activation in responses to their mother's face (while still showing right temporal activation to a stranger's face). ${ }^{87,88}$ In addition, lateralized responses appear to depend on the emotion displayed. Left dominant temporal activation has been observed in response to happy facial expressions, whereas right dominant temporal activation has been obtained to angry expressions. Although it is currently difficult to draw firm conclusions about when and why bilateral responses will be obtained, these findings do suggest that characteristics of face stimuli (e.g., familiarity or emotional content) elicit different processes. Given that the electrophysiological studies have reported differential responses to some of these same face dimensions, the combined use of fNIRS and EEG/ERP might be particularly beneficial for identifying the underlying neural mechanisms here. ${ }^{89-91,80}$

Most of the studies reviewed above used a block design, but there are some studies that have used an adaptation paradigm, often seen in fMRI studies, to study face processing. In an adaptation paradigm, stimuli that are similar in ways that are important to the researcher are presented in succession. After presentation of a sufficient number of trials to elicit neural adaptation, a stimulus that deviates from the dimension of interest is presented (e.g., a male face is presented following the presentation of many different females faces). If the test stimulus is perceived as different from the adapted stimuli, increased hemodynamic responses should be observed. Studies using this technique have produced results that are largely consistent with those obtained with block designs. For example, 5- to 6-month old infants show adaptation in the temporal cortex to frontal but not profile views of faces, whereas 7- to 8-month-old infants show adaptation to frontal and profile views (i.e., perceive the face as the same, regardless of the viewpoint). ${ }^{92}$ A similar developmental trajectory has been reported for infants' recognition of faces that undergo non-rigid transformations (e.g., puffing cheeks or pursing lips). ${ }^{93}$ These results provide converging evidence for the conclusion that with experience, face processing becomes less disrupted by changes in perspective. (Apparently, however, face processing is not disrupted by change in size, even in young infants ${ }^{94}$ ). Finally, it is important to note that adaptation studies have not reported lateralized responses to face stimuli, leading us to wonder whether this technique invokes different and/or additional processes than those invoked in block designs.

Processing of Human Motion-From the early days of life, infants differentiate between and prefer displays containing biological motion (e.g., point light displays of human walkers) as compared with other types of motion (e.g., scrambled or inverted 
displays of human walkers) and have different expectations for the way that human and mechanical entities should move and interact. ${ }^{95-97}$ This has led some researchers to the hypothesis that from the early days of life, we possess specialized networks for the processing of human and mechanical entities. Adult fMRI research consistently reports activation in the medial and anterior part of the STS and motor-related areas in frontal cortex in response to human motion, and these activation patterns differ from those in responses to tools, vehicles, and other nonhuman entities. ${ }^{98-100}$ To assess the extent to which the infant brain responds to these distinctions, Lloyd-Fox and colleagues ${ }^{37}$ presented 5-month-old infants with a video of a woman engaged in actions (moved her eyes, opened her mouth, and moved her hands to play peek-a-boo), and a video of inanimate objects undergoing mechanical movements, on alternating test trials (Figure 8(a)). Stimuli presented during the baseline interval were static images of transport vehicles (e.g., cars and helicopters). Hemodynamic responses were measured from an array of optodes anchored at T3 and T4 (Figure 8(b)). Bilateral temporal activation was obtained in response to the dynamic social but not dynamic nonsocial stimuli. Recent research suggests that even newborns show some selective cortical responses to these events. ${ }^{101}$ A subsequent study ${ }^{102}$ revealed that actions involving the eyes, mouth, or hands, only, produced distinct localized patterns of cortical activation in temporal-frontal areas, suggesting early functional specificity for human action.

Taking a slightly different approach, Grossman and colleagues ${ }^{103}$ assessed hemodynamic responses to human and robotic motion in 4-month-old infants. The infants saw events in which the form of an object (human or robot) was crossed with the motion that the object displayed (human or robot). Similar to the study by Lloyd-Fox and colleagues, optodes were anchored at T3 and T4. Two main findings emerged: (1) areas in the right premotor cortex responded selectively to robot as compared with human motion (regardless of whether the motion was seen in a human or robot form) and (2) left temporal cortex responded selectively to congruent (human-human/robot-robot) as compared with incongruent (human-robot/robot-human) form-motion pairings. Also, by using a crossed design, Biondi and Wilcox ${ }^{104}$ assessed hemodynamic responses in infants aged 7-9 months as they viewed events in which one of two types of hands (human or mechanical) engaged in one of two types of events with a tool (performed a function or underwent articulated motion). One array of optodes was anchored between T3 and T5 and another between T4 and T6 (see Figure 4), so that the cortical areas from which hemodynamic responses were assessed were more posterior than those of the study by Grossman et al. Biondi and Wilcox found widespread bilateral activation in response to the human but not mechanical hand. In addition, a subset of channels in inferior temporal areas showed significantly greater activation to functional than articulated motion. In other words, greater sensitivity to human than mechanical hands was found across the temporal cortex, bilaterally, with select areas specialized for functionally relevant use of tools.

While these studies are the first step toward identifying the cortical networks that mediate processing of human and mechanical motion in the infant brain, there is a lot of work yet to do. For example, there are a number of ways in which the human and mechanical events used in these studies differed (animate versus inanimate motion, self-propelled versus inert, goal-directed versus not goal directed), and we do not know which of these factors are critical to the behavioral and neural responses observed. We suspect that some of these event 
characteristics will elicit overlapping patterns of cortical activation, whereas others may not (See Southgate et al. for recent work on goal representation in the infant brain ${ }^{105}$ ).

Processing of Communicative Intent-In the adults, researchers have identified a complex network of areas in the temporal and frontal cortex that are important for the processing of social cues that signal communicative intent (e.g., mutual gaze, gaze direction, raised eyebrows, smile). ${ }^{106}$ Behavioral and electrophysiological studies have demonstrated sensitivity to these cues from the early months of life. ${ }^{107-109}$ To identify the extent to which the immature brain is functionally specialized to processes such as cues, Grossman and colleagues ${ }^{41}$ showed 4-month-old infants animated faces displaying communicative intent (i.e., mutual gaze accompanied by raised eyebrows and a smile) or control faces (i.e., faces with gestures that did not communicate intent) and measured the hemodynamic responses in the temporal and prefrontal cortex (Figure 9); baseline stimuli were moving cars or geometric shapes. Significant activation was obtained in the right superior temporal cortex and the right frontopolar cortex in response to the communicative intent but not to the control displays. ${ }^{110}$ In subsequent studies, Grossman and colleagues focused their investigations on frontal cortex only. In one study, 5-month-old infants were presented with faces that displayed communicative intent or control faces and activation was obtained in the left dorsal prefrontal cortex to the communicative intent but not to the control displays. ${ }^{111} \mathrm{In}$ another study with 5-month-old infants, hemodynamic responses were measured to (1) someone calling the infant's name as compared with a control name and (2) faces making eye contact as compared with averting gaze. ${ }^{12}$ These two stimuli, which included auditory or visual cues to signal communicative intent, respectively, elicited activation in the adjacent but nonoverlapping areas in the left dorsal prefrontal cortex.

Together, the research in this section suggests that the infant brain responds selectively to biologically and socially relevant information in ways that appear similar to that observed in the adult brain. This research also lays the foundation for identifying early emerging cortical networks that support the processing of faces, bodies, and social cues. Care must be taken, however, in data interpretation: most of the studies reviewed above used baseline events that differed from the test events in many dimensions. The extent to which other baseline events produce similar outcomes would be informative.

\section{Language Development}

A large proportion of fNIRS work in the developmental sciences has focused on the cortical underpinnings of language development, and some of the first fNIRS studies published were language related (for detailed reviews see Refs 29, 113-115). Here, we focus on studies that have helped advance our understanding of the developmental issues. Most of the studies reported here used a no-stimulus baseline and had an array of channels placed bilaterally near T3 and T4.

Phonemic Contrasts-The ability to segment the continuous speech stream into meaningful units is a prerequisite for language acquisition. Behavioral studies have consistently reported that at birth, infants have the capacity to discriminate between speech sounds of almost all languages but by $6-10$ months, they maintain sensitivity only to 
phonemic contrasts that are relevant to their language community (for reviews, see Refs 116-118). fNIRS has been used to investigate the perceptual and neural mechanisms that support the tuning of this fundamental capacity. Minagawa-Kawai and colleagues ${ }^{119}$ investigated the development of cortical responses to phonemic contrasts (speech sounds that crossed a phonemic boundary, as defined by durational information) and nonphonemic contrasts (speech sounds that did not cross a phonemic boundary) from the infants' native Japanese language. Infants aged 3-4 months and 10-11 months showed bilateral temporal activation to phonemic and non-phonemic contrasts. In comparison, infants aged 13-14 months and 25-28 months showed greater hemodynamic responses to phonemic than nonphonemic contrasts, and responses to the phonemic contrasts were left temporal dominant. Although 6-7-month-old infants showed greater hemodynamic responses to phonemic than nonphonemic contrasts, these responses were not left lateralized, leading Minagawa-Kawai and colleagues to hypothesize that a nonlinguistic mechanism was responsible for the differential responses to phonemic and nonphonemic contrasts at this age. Other researchers have reported bilateral temporal responses to phonemic contrasts as defined by vowel or pitch-accent information in newborn, 3-month-old, 4-month-old, and 7-month-old infants, ${ }^{120-123}$ and left-lateralized responses have been obtained in 10-12-month-old infants on the basis of these cues. ${ }^{122,123}$ These data suggest that the age at which lateralized phonemic processing emerges depends on the segmentation cue used.

One interpretation that has been offered for the age-related shift from bilateral to lateralized responses to phonemic contrasts is that early in the first year, phoneme discrimination is based primarily on the acoustic properties of the stimuli (e.g., spectrally simple, rapid changes), which elicit bilateral activation. Once these acoustic signals take on linguistic meaning, phoneme discrimination becomes lateralized to the left temporal cortex. ${ }^{113,115,124}$ This is supported, in part, by the evidence that bilateral temporal activation is obtained to nonspeech sounds (e.g., tones) that can be discriminated on the basis of rapid durational changes in newborns and young infants, as well as in adults. ${ }^{113,115,124-126}$ In comparison, acoustic signals that are slow, modulated, and spectrally diverse (e.g., prosodic in nature) evoke lateralized responses from birth. For example, newborn infants discriminate between phonemes on the basis of a rise in pitch and these contrasts elicit greater hemodynamic responses in the right than the left temporal areas. ${ }^{120}$ In addition, newborn and 3-6-monthold infants show right lateralized responses to slow, modulated, and spectrally diverse tones. ${ }^{125,126}$ In short, while neural responses to phonemic discriminations gradually become (left) lateralized over the first year, neural responses to prosodic discriminations appear to be (right) lateralized from birth. The specific processes by which these responses become lateralized are open to debate.

Language Processing-From the early days of life, infants prefer language to nonlanguage stimuli, prosodic over monotone language stimuli, and native language over novel language stimuli. ${ }^{116,117}$ These and other data have been taken as evidence that humans are predisposed to attend to and learn language, and that the brain may be specialized for this capacity from birth. fNIRS has been used to assess this hypothesis using a number of different types of language and nonlanguage stimuli. 
In the first fNIRS study to investigate regional specificity (lateralization) of early language processing, sleeping newborns were presented with forward (FW) and backward (BW) speech in their native (Italian) language and hemodynamic responses were measured from optodes placed over the right and left temporal lobes. ${ }^{39}$ Greater activation was obtained to FW than BW speech in the left hemisphere, in perisylvian regions (below the Sylvian fissure) and little activation was obtained to either stimulus in the right hemisphere. A leftlateralized response to the mother tongue has been obtained in other fNIRS studies in infants newborn through to 12 months ${ }^{8,127-132}$ and in several fMRI studies. ${ }^{133-135}$ This response appears to be specific to the infants' native language; left-lateralized responses are not obtained to an unfamiliar language. ${ }^{8,132}$ Taken together, these studies suggest early and robust left-lateralized responses to sounds from one's language community (although bilateral responses were reported in one study). ${ }^{34}$

At the same time, there is evidence that the nature of the cortical responses to language stimuli changes during the first year. For example, 5-month-old, but not 3-month-old, infants show left-lateralized responses in the anterior perisylvian cortex to differences in accent, suggesting that between 3 and 5 months, this temporal area becomes more sensitive to subtle linguistic differences. Likewise, even though infants from birth to 12 months show leftlateralized responses in perisylvian regions to their native language (but not to a nonnative language or nonlinguistic stimuli), it is not until the end of the first year that more anterior, and higher level, language areas show left-lateralized responses. ${ }^{8}$ Together, these data suggest an early emerging distributed cortical network for the processing of complex linguistic stimuli, with some cortical structures becoming functionally lateralized before others. fMRI studies confirm the intricate nature of early emerging circuits ${ }^{133,135}$ and highlight the importance of investigating age-related changes in temporal, frontal, and parietal language processing areas. ${ }^{8,136}$

Interestingly, a different pattern of results is obtained when the speech sounds are altered. May and colleagues ${ }^{137}$ assessed newborns' cortical responses to FW and BW speech of the infant's native language (English) and an unfamiliar language (Tagalog), both of which had been low-pass filtered. They obtained bilateral activation to the FW familiar speech and little activation to the FW unfamiliar speech. The interpretation these researchers offered is that low-pass filtering the language stimuli removed much of the durational segmentation information, while retaining prosodic information. Infants could discriminate between the FW familiar and the FW unfamiliar speech on the basis of prosodic cues (as evidenced by different patterns of cortical activation), but without information about rapid consonant changes, processing of the familiar language elicited bilateral activation. However, bilateral activation was also obtained to the BW familiar and unfamiliar speech, which is more difficult to explain. Studies investigating infant's hemodynamic responses to normal as compared with flattened speech have also produced puzzling results. ${ }^{138,139}$ For example, 3month-old infants show greater activation to normal than flattened speech in the right hemisphere, whereas 10-month-old infants show greater activation to flattened than normal speech in the left hemisphere. In summary, when the temporal and spectral properties of natural language stimuli are altered, different patterns of cortical activation emerge and, as yet, these patterns are not fully understood. It is possible that flattened speech sounds, which are arguably unnatural and biologically invalid, are not easily categorized by infants as 
language or nonlanguage auditory stimuli, so do not consistently elicit language (or nonlanguage) processing mechanisms.

Finally, there are a number of studies that have investigated cortical responses to speech and nonspeech sounds (e.g., nonspeech vocalizations with and without prosody, monkey vocalizations, phase-scrambled sounds, nonspeech environmental sounds) in infants 3-7 months of age. ${ }^{12,140-142}$ Different patterns of neural activation are typically obtained to speech than nonspeech sounds, which is an important piece of converging evidence for early specificity in language processing. However, the nature of these differences is not consistent across studies and because of differences in procedures and stimuli, it is difficult to draw firm conclusions about the patterns of functional activation observed, as a whole.

Language Learning-Some researchers have focused on early emerging learning mechanisms. Gervain and colleagues ${ }^{143,10}$ investigated newborns' ability to discriminate between three-syllable sequences that conformed to an $\mathrm{ABB} / \mathrm{AAB}$ or an $\mathrm{ABC}$ pattern (Figure 10). They reported greater activation to $\mathrm{ABB} / \mathrm{AAB}$ patterns than $\mathrm{ABC}$ patterns in temporal and frontal areas, and this effect was stronger in the left hemisphere. There was also some evidence that hemodynamic responses to $\mathrm{ABB} / \mathrm{AAB}$ patterns increased during learning. These results suggest an early existing neural mechanism for extracting repetitive structure from linguistic stimuli. A less clear pattern of results was obtained with 7- and 9month-old infants, ${ }^{144}$ raising questions about the developmental time course of this mechanism. Future research will need to address whether this response pattern is language specific or can be explained by domain-general learning mechanisms.

Nakano and colleagues ${ }^{121}$ investigated cortical responses during the learning of a phoneme. Infants aged 3-4 months were first habituated to a phoneme (/ba/) and then tested with the same phoneme or a novel phoneme (/pa/). Two findings emerged: (1) bilateral temporal activation was obtained during habituation and test trials in both the groups, although fewer channels were activated in later than earlier trials and (2) bilateral frontal-parietal activation was obtained in the first few habituation trials for all infants but in test trials for only the infants who heard the novel phoneme. That is, temporal activation was obtained to familiar and novel phonemes, but frontal-parietal activation was only obtained when the phoneme was perceived as novel. Other researchers have reported similar results with newborns, although temporal responses were lateralized to the left whereas frontal-parietal responses were lateralized to the right, as is typically observed in adults. ${ }^{128,129}$ In addition, there is evidence that cortical responses are greater to syllables that follow universal constraints than those that have a composition that is infrequent across languages. ${ }^{129}$ One interpretation of this pattern of results is that the human brain possesses experience-independent linguistic biases that facilitate phoneme discrimination and shape language learning. What remains an open question is the extent to which frontal-parietal responses to novelty are specific to linguistic stimuli or are elicited by other novel stimuli as well. In other words, to what extent is the part of this linguistic circuit that facilitates novelty detection shared with circuits devoted to processing other types of (nonlinguistic) stimuli? 


\section{CONCLUSION}

The use of fNIRS in the developmental sciences has advanced rapidly over the last 16 years, from studies using a few channels to investigate basic perceptual processes to multichannel studies investigating more complex cognitive, linguistic, and social behavior. The studies reviewed here demonstrate that from the early months of life, the human brain is specialized to process select types of information. For example, an area in the temporal cortex responds selectively when the individuation process is engaged and frontal-temporal areas respond selectively to the movement of faces, bodies, and hands, respectively. Research has also identified changes in patterns of neural activation with time and experience. For example, shape processing activates parietal areas early but not later in the first year. Processing of phonemic contrasts elicits bilateral temporal activation in the first few months of life, and left dominant temporal activation in later months. These and related findings lay the groundwork for the identification of early cortical networks dedicated to the processing of physical objects, social objects, and linguistic stimuli that are shaped by experience.

At the same time, as with any emerging field, there are limitations to the conclusions that can be drawn on the basis of the current findings. As the field moves forward, we offer some suggestions as to how researchers can optimize the use of fNIRS in the developmental sciences. We keep in mind that one goal of fNIRS research is to inform developmental theory in ways not possible with behavioral data alone.

\section{Studies That Answer Developmental Questions}

In order to fully understand the developing brain, we must learn more about the neural mechanisms that underlie age-related changes in behavior. To date, few fNIRS studies have been truly developmental in nature. A limited number of studies have investigated hemodynamic responses to a given task in different age groups. ${ }^{56,61,119,121}$ There are no studies, of which we are aware, that have assessed changes in brain and behavior in individuals over time.

\section{Studies That Answer Questions About Learning Mechanisms}

One of the goals of developmental research is to identify factors that mediate, predict, or support changes in behavior. Only a few studies have investigated hemodynamic responses as a result of experiential manipulation or training. ${ }^{11,121,141,143,144}$ Such studies have the potential to identify mechanisms that facilitate learning and underlie changes in the way infants perceive and interpret their world.

\section{Studies That Address Individual Differences in Brain and Behavior}

Many of the developmental research studies on cognitive and social behaviors are complex in nature and large individual differences are sometimes observed, obscuring group results. An individual difference approach, currently rare in fNIRS research (but see Refs 119), can help identify factors, or groups of factors, that can explain variability in patterns of cortical activation and performance. There are approaches (e.g., cross-cultural studies) that would allow us to identify the extent to which brain and behavioral responses are common within and across groups of individuals. ${ }^{143}$

Wiley Interdiscip Rev Cogn Sci. Author manuscript; available in PMC 2016 August 10. 


\section{Standardization of Probe Placement, Data Processing, and Data Analysis}

One of the greatest challenges the field currently faces is difficulty in comparing results across studies. Research labs use very different approaches to probe placement, data processing, and data analysis. Standardization of these techniques, along with the development of infant craniocerebral maps to help guide localization of responses, would significantly enhance our capacity to interpret and compare results across studies.

\section{Strong Predictions and Using fNIRS to Inform Theory}

Now that we have some information about the functional organization of the infant brain, we are in a better position to make stronger a priori predictions about the patterns of responses we expect to obtain. Even more exciting, however, is that fNIRS data, like fMRI data, ${ }^{3}$ can be used to inform developmental theory. For example, patterns of neural activation can provide novel information about the engagement of processes that is not evident in behavioral tasks.

\section{Clinical Applications}

There is a need for noninvasive procedures to identify infants at risk for developmental disorders. Findings from fNIRS studies that investigate patterns of neural activation in atypically developing infants can inform the development of early assessment protocols aimed at identifying infants at risk. These findings might also inform the development of intervention strategies.

\section{Functional Connectivity}

Adult fMRI studies, conducted during a resting state, have identified spatially synchronized spontaneous fluctuations in cerebral blood oxygenation. These patterns are thought to represent functional connectivity within and between cortical areas. Recent studies with infants ${ }^{145-147}$ have also identified patterns of connectivity, which have the potential to reveal information about developing cortical networks. That is, changes in resting state connectivity, a self-organizing process, can be used to help explain changes in how the developing brain consolidates and stores information.

\section{Hyperscanning}

A newly emerging paradigm in the neurosciences in hyperscanning, a term for measuring brain activity from two or more participants simultaneously. ${ }^{148}$ In fNIRS, this involves the analysis of the interaction of hemodynamic responses of the multiple participants. This would provide invaluable information about the social processes that facilitate learning in the infant.

\section{Freely Moving Participants}

Using currently available devices, infant participants have some liberty in movement but are tethered, via optical fibers, to a stationary imaging device. Although the challenges associated with developing devices and headgear that can support quality data collection with freely moving infants are immense, this capability may not be as distant as once thought. ${ }^{149}$ 


\section{Acknowledgments}

The writing of this paper was supported by R01-HD057999 to the first author.

\section{References}

1. Jobsis FF. Noninvasive infrared monitoring of cerebral and myocardial sufficiency and circulatory parameters. Science. 1977; 198:1264-1267. [PubMed: 929199]

2. Meek JH, Firbank M, Elwell CE, Atkinson J, Braddick O, Wyatt JS. Regional haemodynamic responses to visual stimulation in awake infants. Pediatr Res. 1998; 43:840-843. [PubMed: 9621996]

3. Mather M, Cacioppo JT, Kanwisher N. How fMRI can inform cognitive theories. Perspect Psychol Sci. 2013; 8:108-113. DOI: 10.1177/1745691612469037 [PubMed: 23544033]

4. Poldrack RA. Can cognitive processing be inferred from neuroimaging data? Trends Cogn Sci. 2006; 10:59-63. DOI: 10.1016/j.tics.2005.12.004 [PubMed: 16406760]

5. Machery E. In defense of reverse inference. Brit J Phil Sci. 2014; 65:251-267. DOI: 10.1093/bjps/ axs044

6. Aslin R. Questioning the questions that have been asked about the infant brain using near-infrared spectroscopy. Cogn Neuropsy. 2012; 29:7-33. DOI: 10.1080/02643294.2012.654773

7. Karmiloff-Smith A. Neuroimaging of the developing brain: taking "developing" seriously. Hum Brain Mapp. 2010; 31:934-941. DOI: 10.1002/hbm.21074 [PubMed: 20496384]

8. Pettito LA, Berens MS, Kovelman I, Dubins MH, Jasinka K, Shalinsky M. The "perceptual wedge hypothesis" as the basis for bilingual babies' phonetic processing advantage: new insights from fNIRS brain imaging. Brain Lang. 2012; 121:130-143. DOI: 10.1016/j.bandl.2011.05.003 [PubMed: 21724244]

9. Sevy ABG, Bortfeld H, Huppert TJ, Beauchamp MS, Tonini RE, Oghali JS. Neuroimaging with near-infrared spectroscopy demonstrates speech-evoked activity in the auditory cortex of deaf children following cochlear implantation. Hear Res. 2010; 270:39-47. DOI: 10.1016/j.heares. 2010.09.010 [PubMed: 20888894]

10. Gervain J, Macagno F, Cogoi S, Pena M, Mehler J. The neonate brain detects speech structure. Proc Natl Acad Sci USA. 2008; 105:14222-14227. [PubMed: 18768785]

11. Wilcox T, Hirshkowitz A, Hawkins L, Boas DA. The effect of color priming on infant brain and behavior. Neuroimage. 2014; 85:302-313. DOI: 10.1016/j.neuroimage.2013.08.045 [PubMed: 24007805]

12. Chance B, Zhuang Z, Unah C, Alter C, Lipton L. Cognition-activated low-frequency modulation of light absorption in human brain. Proc Natl Acad Sci USA. 1993; 90:3770-3774. [PubMed: 8475128]

13. Hoshi Y, Tamura M. Dynamic multichannel near-infrared optical imaging of human brain activity. J Appl Physiol. 1993; 75:1842-1846. [PubMed: 8282640]

14. Villringer A, Planck J, Hock C, Schleinkofer L, Dirnagl U. Near infrared spectroscopy (NIRS): a new tool to study hemodynamic changes during activation of brain function in human adults. Neurosci Lett. 1993; 154:101-104. [PubMed: 8361619]

15. Kato T, Kamei A, Takashima S, Ozaki T. Human visual cortical function during photic stimulation monitoring by means of near-infrared spectroscopy. J Cereb Blood Flow Metab. 1993; 13:516520. [PubMed: 8478409]

16. Boas DA, Dale AM, Franceschini MA. Diffuse optical imaging of brain activation: approaches to optimizing image sensitivity, resolution, and accuracy. Neuroimage. 2004; 23:S275-S288. DOI: 10.1016/j.neuroimage.2004.07.011 [PubMed: 15501097]

17. Strangman G, Franceschini MA, Boas DA. Factors affecting the accuracy of near-infrared spectroscopy concentration calculations for focal changes in oxygenation parameters. Neuroimage. 2003; 18:865-879. [PubMed: 12725763]

18. Sato H, Kiguchi M, Kawaguchi F, Maki A. Practicality of wavelength selection to improve signalto-noise ratio in infrared spectroscopy. Neuroimage. 2004; 21:1554-1562. [PubMed: 15050579]

Wiley Interdiscip Rev Cogn Sci. Author manuscript; available in PMC 2016 August 10. 
19. Gratton G, Goodman-Wood MR, Fabiani M. Comparison of neuronal and hemodynamic measures of the brain response to visual stimulation: an optical imaging study. Hum Brain Mapp. 2001; 13:13-25. [PubMed: 11284043]

20. Kleinschmidt A, Obrig H, Requardt M, Merboldt KD, Dirnagl U, Villringer A, Frahm J. Simultaneous recording of cerebral blood oxygenation changes during human brain activation by magnetic resonance imaging and near-infrared spectroscopy. J Cerebr Blood F Met. 1996; 16:817826.

21. Strangman G, Culver JP, Thompson JH, Boas DA. A quantitative comparison of simultaneous BOLD fMRI and NIRS recordings during functional brain activation. Neuroimage. 2002; 17:719731. [PubMed: 12377147]

22. Villringer A, Chance B. Non-invasive optical spectroscopy and imaging of human brain function. Trends Neurosci. 1997; 20:435-442. [PubMed: 9347608]

23. Huppert TJ, Hoge RD, Diamond SG, Franceschini MA, Boas DA. A temporal comparison of BOLD, ASL, and NIRS hemodynamic responses to motor stimuli in adult humans. Neuroimage. 2006; 29:368-382. [PubMed: 16303317]

24. Franceschini AG, Boas DA. Noninvasive measure of neuronal activity with near-infrared optical imaging. Neuroimage. 2004; 21:372-386. DOI: 10.1016/j.neuroimage.2003.09.040 [PubMed: 14741675]

25. Jasdzewski G, Strangman G, Wagner J, Kwong KK, Poldrack RA, Boas DA. Differences in the hemodynamic response to event-related motor and visual paradigms as measured by near-infrared spectroscopy. Neuroimage. 2003; 20:479-488. [PubMed: 14527608]

26. Fransson P, Skiold B, Engstrom M, Hallberg B, Mosskin M, Aden U, Lagercrantz H, Blennow M. Spontaneous brain activity in the newborn brain during natural sleep-an fMRI study in infants born at full term. Pediatr Res. 2009; 66:301-305. [PubMed: 19531974]

27. Tsuzuki D, Dan I. Spatial registration for functional near-infrared spectroscopy: from channel position on the scalp to cortical location in individual and group analyses. Neuroimage. 2014; 85:92-103. DOI: 10.1016/j.neuroimage.2013.07.025 [PubMed: 23891905]

28. Okamoto M, Dan H, Sakamoto K, Takeo K, Shimizu K, Kohno S, Oda I, Isobe S, Suzuki T, Kohyama K, et al. Three-dimensional probabilistic anatomical craniocerebral correlation via the international 10-20 system oriented for transcranial functional brain mapping. Neuroimage. 2004; 21:99-111. DOI: 10.1016/j.neuroimage.2003.08.026 [PubMed: 14741647]

29. Minagawa-Kawai Y, Mori K, Hebden JC, Dupoux E. Optical imaging of infants' neurocognitive development: recent advances and perspectives. Dev Neurobiol. 2008; 68:712-728. DOI: 10.1002/ dneu.20618 [PubMed: 18383545]

30. Wolf M, Ferrari M, Quaresima V. Progress of near-infrared spectroscopy and topography for brain and muscle clinical applications. J Biomed Opt. 2007; 12:062104. [PubMed: 18163807]

31. Scholkmann F, Kleiser S, Metz AJ, Zimmermann R, Pavia JM, Wolf U, Wolf M. A review on continuous wave functional near-infrared spectroscopy and imaging instrumentation and methodology. Neuroimage. 2014; 85:6-27. DOI: 10.1016/j.neuroimage.2013.05.004 [PubMed: 23684868]

32. Torricelli A, Contini D, Pifferi A, Caffini M, Re R, Zucchelli L, Spinelli L. Time domain functional NIRS imaging for human brain mapping. Neuroimage. 2014; 85:28-50. DOI: 10.1016/ j.neuroimage.2013.05.106 [PubMed: 23747285]

33. Hyde DC, Boas DA, Blair C, Carey S. Near-infrared spectroscopy shows right parietal specialization for number in pre-verbal infants. Neuroimage. 2010; 53:647-652. DOI: 10.1016/ j.neuroimage.2010.06.030 [PubMed: 20561591]

34. Taga G, Asakawa K. Selectivity and localization of cortical response to auditory and visual stimulation in awake infants aged 2 to 4 months. Neuroimage. 2007; 36:1246-1252. DOI: 10.1016/j.neuroimage.2007.04.037 [PubMed: 17524672]

35. Watanabe H, Homae F, Nakano T, Taga G. Functional activation in diverse regions of the developing brain of human infants. Neuroimage. 2008; 43:346-357. [PubMed: 18691660]

36. Krekelberg B, Boynton GM, Wezel RJA. Adaptation: from single cells to BOLD signals. Trends Neurosci. 2006; 29:250-256. [PubMed: 16529826]

Wiley Interdiscip Rev Cogn Sci. Author manuscript; available in PMC 2016 August 10. 
37. Lloyd-Fox S, Blasi A, Volein A, Everdell N, Elwell C, Johnson MH. Social perception in infancy: a near infrared spectroscopy study. Child Dev. 2009; 80:986-999. [PubMed: 19630889]

38. Lloyd-Fox S, Blasi A, Elwell CE. Illuminating the developing brain: the past, present and future of functional near infrared spectroscopy. Neurosci Biobehav Rev. 2010; 34:269-284. DOI: 10.1016/ j.neubiorev.2009.07.008 [PubMed: 19632270]

39. Pena M, Maki A, Kovacic D, Dehaene-Lambertz G, Koizumi H, Bouquet F, Mehler J. Sounds and silence: an optical topography study of language recognition at birth. Proc Natl Acad Sci USA. 2003; 100:11702-11705. DOI: 10.1073/pnas.1934290100 [PubMed: 14500906]

40. Wilcox T, Bortfeld H, Woods R, Wruck E, Boas DA. Using near-infrared spectroscopy to assess neural activation during object processing in infants. J Biomed Opt. 2005; 10:011010.doi: $10.1117 / 1.1852551$

41. Grossmann T, Johnson MH, Lloyd-Fox S, Blasi A, Delganni F, Elwell C, Csibra G. Early cortical specialization for face-to-face communication in human infants. Proc R Soc B. 2008; 275:28032811. DOI: $10.1098 / \mathrm{rspb} .2008 .0986$

42. Csibra G, Tucker L, Johnson MH. Differential frontal cortex activation before anticipatory and reactive saccades in infants. Infancy. 2001; 2:159-174.

43. Brigadoi S, Ceccherini L, Cutini S, Scarpa F, Scatturin P, Sleb J, Gagnon L, Boas DA, Cooper RJ. Motion artifacts in functional near-infrared spectroscopy: a comparison of motion correction techniques applied to real cognitive data. Neuroimage. 2014; 85:181-191. DOI: 10.1016/ j.neuroimage.2013.04.082 [PubMed: 23639260]

44. Delpy DT, Cope M, van der Zee P, Arridge S, Wray S, Wyatt J. Estimation of optical pathlength through tissue from direct time of flight measurement. Phys Med Biol. 1988; 33:1433-1442. [PubMed: 3237772]

45. Tak S, Ye JC. Statistical analysis of fNIRS data: a comprehensive review. Neuroimage. 2014; 85:72-91. DOI: 10.1016/j.neuroimage.2013.06.016 [PubMed: 23774396]

46. Bar M. A cortical mechanism for triggering top-down facilitation in visual object recognition. J Cogn Neurosci. 2003; 15:600-609. [PubMed: 12803970]

47. Devlin JT, Russell RP, Davis MH, Price CJ, Moss HE, Fadili MJ, Tyler LK. Is there an anatomical basis for category-specificity? Semantic memory studies in PET and fMRI. Neuropsychologia. 2002; 40:54-75. [PubMed: 11595262]

48. Grill-Spector K. The neural basis of object perception. Curr Opin Neurobiol. 2003; 13:159-166. [PubMed: 12744968]

49. Haxby JV, Gobbini MI, Furey ML, Ishai A, Schouten JL, Pietrini P. Distributed and overlapping representations of faces and objects in ventral temporal cortex. Science. 2001; 293:2425-2430. DOI: 10.1126/science.1063736 [PubMed: 11577229]

50. Humphreys GW, Price CJ, Riddoch MJ. From objects to names: a cognitive neuroscience approach. Psychol Res. 1999; 1999:118-130. [PubMed: 10472198]

51. Kanwisher, N. The ventral visual object pathway in humans: evidence from fMRI. In: Chalupa, L.; Werner, J., editors. The Visual Neurosciences. Cambridge, MA: MIT Press; 2003. p. 1179-1189.

52. Kourtzi Z, Connor CE. Neural representations for object perception: structure, category, and adaptive coding. Annu Rev Neurosci. 2011; 34:45-67. DOI: 10.1146/annurevneuro-060909-153218 [PubMed: 21438683]

53. Mahon BH, Caramazza A. What drives the organization of object knowledge in the brain? Trends Cogn Sci. 2011; 15:97-103. DOI: 10.1016/j.tics.2011.01.004 [PubMed: 21317022]

54. Baillargeon, R.; Carey, S. Core cognition and beyond: the acquisition of physical and numerical knowledge. In: Pauen, S., editor. Early Childhood Development and Later Outcome. Cambridge, England: Cambridge University Press; 2012. p. 33-65.

55. Wilcox T, Haslup J, Boas DA. Dissociation of processing of featural and spatiotemporal information in the infant cortex. Neuroimage. 2010; 53:1256-1263. DOI: 10.1016/j.neuroimage. 2010.06.064 [PubMed: 20603218]

56. Wilcox T, Stubbs J, Hirshkowitz A, Boas DA. Object processing and functional organization of the infant cortex. Neuroimage. 2012; 62:1833-1840. DOI: 10.1016/j.neuroimage.2012.05.039 [PubMed: 22634218] 
57. Wilcox T, Bortfeld H, Woods R, Wruck E, Boas DA. Hemodynamic response to featural changes in the occipital and inferior temporal cortex in infants: a preliminary methodological exploration. Dev Sci. 2008; 11:361-370. DOI: 10.1111/j.1467-7687.2008.00681.x [PubMed: 18466370]

58. Wilcox T, Bortfeld H, Armstrong J, Woods R, Boas DA. Hemodynamic response to featural and spatiotemporal information in the infant brain. Neuropsychologia. 2009; 47:657-662. [PubMed: 19071143]

59. Wilcox T. Object Individuation: Infants' use of shape, size, pattern, and color. Cognition. 1999; 72:125-166. [PubMed: 10553669]

60. Wilcox T, Woods R, Chapa C, McCurry S. Multisensory exploration and object individuation in infants. Dev Psychol. 2007; 43:479-495. [PubMed: 17352554]

61. Wilcox T, Hawkins L, Hirshkowitz A, Boas DA. Cortical activation to object shape and speed of motion during the first year. NeuroImage. 2014; 99:129-141. DOI: 10.1016/j.neuroimage. 2014.04.082 [PubMed: 24821531]

62. Malach R, Reppas JB, Benson RR, Kwong KK, Jiang H, Kennedy WA, Ledden PJ, Brady TJ, Rosen BR, Tootell RBH. Object-related activity revealed by functional magnetic resonance imaging in human occipital cortex. Proc Natl Acad Sci USA. 1995; 92:8135-8139. [PubMed: 7667258]

63. Honda Y, Nakato E, Otsuka Y, Kanazawa S, Kojima S, Yamaguchi MK, Kakigi R. How do infants' perceive scrambled faces? a near-infrared spectroscopic study. Brain Res. 2010; 1308:137-146. DOI: 10.1016/j.brainres.2009.10.046 [PubMed: 19874803]

64. Watanabe H, Homae F, Taga G. General to specific development of functional activation in the cerebral cortexes of 2- to 3-month-old infants. Neuroimage. 2010; 50:1536-1544. [PubMed: 20109561]

65. Bachevalier J, Mishkin M. Effects of selective neonatal temporal lobe lesions on visual recognition in rhesus monkeys. J Neurosci. 1994; 14:2128-2139. [PubMed: 8158261]

66. Kourtzi Z, Kanwisher N. Representation of perceived object shape by the human lateral occipital complex. Science. 2001; 293:1506-1509. [PubMed: 11520991]

67. Murray SO, Schrater P, Kersten D. Perceptual group and the interactions between visual cortical areas. Neural Netw. 2004; 17:695-705. DOI: 10.1016/j.neunet.2004.03.010 [PubMed: 15288893]

68. Oliver RT, Geiger EJ, Lewandowski BC, Thompson-Schill SL. Remembrance of things touched: how sensorimotor experience affects the neural instantiation of object form. Neuropsychologia. 2009; 47:239-247. [PubMed: 18760292]

69. Peuskens H, Claeys KG, Todd JT, Norman JF, Van Hecke P, Orban GA. Attention to 3-D shape, 3D motion, and texture in 3-D structure from motion displays. J Cogn Neurosci. 2004; 16:665-682. [PubMed: 15165355]

70. Thompson-Schill SL. Neuroimaging studies of semantic memory: inferring "how" from "where". Neuropsychologia. 2003; 41:280-292. [PubMed: 12457754]

71. Aguiar A, Baillargeon R. Developments in young infants' reasoning about occluded objects. Cogn Psychol. 2002; 45:267-336. [PubMed: 12528903]

72. Schweinle A, Wilcox T. Sex differences in infants' ability to represent complex event sequences. Infancy. 2004; 6:333-359.

73. Spelke ES, Kestenbaum R, Simons DJ, Wein D. Spatiotemporal continuity, smoothness of motion and object identity in infancy. Brit J Dev Psychol. 1995; 13:113-143.

74. Wilcox T, Schweinle A. Infants' use of speed of motion to individuate objects in occlusion events. Infant Behav Dev. 2003; 26:1833-1840.

75. Mondloch, CJ.; Le Grand, R.; Maurer, D. Perceptual Expertise: Bridging Brain and Behaviour. New York: Oxford University Press; 2010. Chapter 3, Development of expertise in face recognition; p. 67-106.

76. Frankenhuis, WE.; Barrett, HC.; Johnson, SP. People Watching: Social, Perceptual, and Neurophysiological Studies of Body Perception. New York: Oxford University Press; 2013. Chapter 8, Developmental origins of biological motion perception; p. 121-138.

77. Tomasello M, Carpenter M, Call J, Behne T, Moll H. Undetstanding and sharing intentions: the origins of cultural cognition. Behav Brain Sci. 2005; 28:675-735. [PubMed: 16262930] 
78. Duchaine, B.; Yovel, G. Face Recognition. In: Basbaum, AI.; Kaneko, A.; Shepherd, GM.; Westheimer, G., editors. The Senses: A Comprehensive Reference. Vol. 2. San Diego: Academic Press; 2008. p. 329-358.Vision II

79. Grossmann, T.; Vaish, A. Reading faces in infancy: developing a multilevel analysis of a social stimulus. In: Striano, T.; Reid, V., editors. Social Cognition: Development, Neuroscience and Autism. Oxford: Blackwell; 2008. p. 167-180.

80. Righi, G.; Nelson, CA. The neural architecture and developmental course of face processing. In: Rubenstein, JLR.; Rakic, P., editors. Comprehensive Developmental Neuroscience: Neural Circuit Development and Function in the Healthy and Diseased Brain. Oxford: Academic Press; 2013. p. 331-350.

81. Otsuka Y, Nakato E, Kanazawa S, Yamaguchi MK, Watanabe S, Kakagi R. Neural activation to upright and inverted faces in infants measured by near infrared spectroscopy. Neuroimage. 2007; 34:399-406. DOI: 10.1016/j.neuroimage.2006.08.013 [PubMed: 16997577]

82. Ichikawa H, Kanazawab S, Yamaguchi MK, Kakigi R. Infant brain activity while viewing facial movement of point-light displays as measured by near-infrared spectroscopy (NIRS). Neurosci Lett. 2010; 482:90-94. [PubMed: 20609380]

83. Nakato E, Otsuka Y, Kanazawa S, Yamaguchi MK, Watanabe S, Kakagi R. When do infants differentiate profile face from frontal face? A near-infrared spectroscopic study. Hum Brain Mapp. 2009; 30:462-472. [PubMed: 18095284]

84. Cohen LB, Strauss MS. Concept acquisition in the human infant. Child Dev. 1979; 50:419-424. [PubMed: 487881]

85. Fagan JF. Infants' recognition of invariant features of faces. Child Dev. 1976; 47:627-638.

86. Pascalis O, de Haan M, Nelson CA, de Schonen S. Longterm recognition memory for faces assessed by visual paired comparison in 3- and 6-month-old infants. J Exp Psychol Learn. 1998; 24:249-260.

87. Nakato E, Otsuka Y, Kanazawa S, Yamaguchi MK, Honda Y, Kakigi R. I know this face: Neural activity during mother' face perception in 7- to 8-month-old infants as investigated by nearinfrared spectroscopy. Early Hum Dev. 2011; 87:1-7. DOI: 10.1016/j.earlhumdev.2010.08.030 [PubMed: 21111549]

88. Nakato E, Otsuka Y, Kanazawa S, Yamaguchi MK, Honda Y, Kakigi R. Distinct differences in the pattern of hemodynamic response to happy and angry facial expressions in infants-a nearinfrared spectroscopic study. Neuroimage. 2011; 54:1600-1606. DOI: 10.1016/j.neuroimage. 2010.09.021 [PubMed: 20850548]

89. de Haan M, Pascalis O, Johnson MH. Specialization of neural mechanisms underlying face recognition in human infants. J Cogn Neurosci. 2002; 14:199-209. [PubMed: 11970786]

90. de Haan M, Nelson CA. Recognition of the mother's face by six-month-old infants: A neurobehavioral study. Child Dev. 1997; 68:187-210. [PubMed: 9179998]

91. de Haan M, Nelson CA. Brain activity differentiates face and object processing in 6-month-old infants. Dev Psychol. 1999; 35:1113-1121. [PubMed: 10442879]

92. Kobayashi M, Otsuka Y, Nakato E, Kanazawa S, Yamaguchi MK, Kakagi R. Do infants represent the face in a viewpoint-invariant manner? neural adaptation study as measured by near-infrared spectroscopy. Front Hum Neurosci. 2011; 5:1-12. [PubMed: 21283556]

93. Kobayashi M, Otsuka Y, Kanazawa S, Yamaguchi MK, Kakigi R. The processing of faces across non-rigid facial transformation develops at 7 month of age: a fNIRS-adaptation study. BMC Neurosci. 2014; 15:1-8. [PubMed: 24380503]

94. Kobayashi M, Otsuka Y, Kanazawa S, Yamaguchi MK, Kakigi R. Size-invariant representation of face in infant brain: an fNIRS-adaptation study. NeuroReport. 2012; 23:984-988. DOI: 10.1097/ wnr.0b013e32835a4b86 [PubMed: 23090420]

95. Fox R, McDaniel C. The perception of biological motion by human infants. Science. 1982; 218:486-487. [PubMed: 7123249]

96. Hirai M, Hiraki K. An event-related potentials study of biological motion perception in human infants. Cogn Brain Res. 2005; 22:301-304. DOI: 10.1016/j.cogbrainres.2004.08.008

97. Yoon JMD, Johnson SC. Biological motion displays elicit social behavior in 12-month-olds. Child Dev. 2009; 80:1069-1075. [PubMed: 19630894] 
98. Beauchamp MS, Lee KE, Haxby JV, Martin A. Parallel visual motion processing streams for manipulable objects and human movements. Neuron. 2002; 34:149-159. [PubMed: 11931749]

99. Beauchamp MS, Lee KE, Haxby JV, Martin A. FMRI responses to video and point-light displays of moving humans and manipulable objects. J Cogn Neurosci. 2003; 15:991-1001. [PubMed: 14614810]

100. Morris JP, Pelphrey KA, McCarthy G. Perceived causality influences brain activity evoked by biological motion. Soc Neurosci. 2008; 3:16-25. DOI: 10.1080/17470910701476686 [PubMed: 18633843]

101. Farroni T, Chiarelli AM, Lloyd-Fox S, Massaccesi S, Merla A, di Gangi V, Mattarello T, Faraguna D, Johnson MH. Infant cortex responds to other humans from shortly after birth. Sci Rep. 2013; 3:1-5. DOI: 10.1038/srep02851

102. Lloyd-Fox S, Blasi A, Everdell N, Elwell CE, Johnson MH. Selective cortical mapping of biological motion processing in young infants. J Cogn Neurosci. 2011; 23:2521-2532. [PubMed: 20954934]

103. Grossmann T, Cross ES, Ticini LF, Daum MM. Action observation in the infant brain: the role of body form and motion. Soc Neurosci. 2013; 8:22-30. DOI: 10.1080/17470919.2012.696077 [PubMed: 22694145]

104. Biondi, M.; Wilcox, T. Processing of biological and mechanical motion in the infant brain. Poster presented at XIX Biennial International Conference on Infant Studies; Berlin, Germany. 3-5 July, 2014;

105. Southgate V, Begus K, Lloyd-Fox S, di Gangi V, Hamilton A. Goal representation in the infant brain. Neuroimage. 2014; 85:294-301. DOI: 10.1016/j.neuroimage.2013.08.043 [PubMed: 23994126]

106. Adolphs R. Cognitive neuroscience of human social behaviour. Nat Rev Neurosci. 2003; 4:165178. DOI: $10.1038 /$ nrn1056 [PubMed: 12612630 ]

107. Carver, LJ.; Cornew, L. The development of social information gathering in infancy: a model of neural substrates and developmental mechanisms. In: de Haan, M.; Gunnar, MR., editors. Handbook of Developmental Social Neuroscience. New York: Guilford Press; 2009. p. 122-141.

108. Csibra G, Gergely G. Natural pedagogy. Trends Cogn Sci. 2009; 13:148-153. DOI: 10.1016/j.tics. 2009.01.005 [PubMed: 19285912]

109. Mundy P, Newell L. Attention, joint attention, and social cognition. Curr Dir Psychol Sci. 2007; 16:269-274. DOI: 10.1111/j.1467-8721.2007.00518.x [PubMed: 19343102]

110. Grossmann T, Lloyd-Fox S, Johnson MH. Brain responses reveal young infants' sensitivity to when a social partner follows their gaze. Dev Cogn Neurosci. 2013; 6:155-161. DOI: 10.1016/ j.den.2013.09.004 [PubMed: 24185257]

111. Grossmann T, Johnson MH. Selective prefrontal cortex responses to joint attention in early infancy. Biol Lett. 2010; 6:540-543. DOI: 10.1098/rsbl.2009.1069 [PubMed: 20106861]

112. Grossmann T, Parise E, Friederici A. The detection of communicative signals directed at the self in infant prefrontal cortex. Front Hum Neurosci. 2010; 4:1-5. DOI: 10.3389/fnhum.2010.00201 [PubMed: 20204154]

113. Obrig H, Rossi S, Telkemeyer S, Wartenburger I. From acoustic segmentation to language processing: evidence from optical imaging. Front Neuroenergetics. 2010; 2:1-12. DOI: 10.3389/ fnene.2010.00013 [PubMed: 20162100]

114. Quaresima V, Bisconti S, Ferrari M. A brief review on the use of functional near-infrared spectroscopy (fNIRS) for language imaging studies in human newborns and adults. Brain Lang. 2012; 121:79-89. DOI: 10.1016/j.bandl.2011.03.009 [PubMed: 21507474]

115. Rossi S, Telkemeyer S, Wartenburger I, Obrig H. Shedding light on words and sentences: nearinfrared spectroscopy in language research. Brain Lang. 2012; 121:152-163. DOI: 10.1016/ j.bandl.2011.03.008 [PubMed: 21546074]

116. Kuhl PK. Early language acquisition: cracking the speech code. Nat Rev Neurosci. 2004; 5:831843. [PubMed: 15496861]

117. Saffran, JR.; Werker, JF.; Werner, LA. The Infant's Auditory World: Hearing, Speech, and the Beginnings of Language. In: Damon, W.; Lerner, RM., editors. The Handbook of Child Psychology. New York: Wiley; 2006. p. 58-108. 
118. Werker JF, Yeung HH. Infant speech perception bootstraps word learning. Trends Cogn Sci. 2005; 2005:519-527. [PubMed: 16202639]

119. Minagawa-Kawai Y, Mori K, Naoi N, Kojima S. Neural attunement processes in infants during the acquisition of a language-specific phonemic contrast. J Neurosci. 2007; 27:315-321. DOI: 10.1523/jneurosci.1984-06.2007 [PubMed: 17215392]

120. Arimitsu T, Uchida-Ota M, Yagihashi T, Kojima S, Watanabe S, Hokuto I, Ikeda K, Takahashi T, Minagawa-Kawai Y. Functional hemispheric specialization in processing phonemic and prosodic auditory changes in neonates. Front Psychol. 2011; 2:1-10. DOI: 10.3389/fpsyg.2011.00202 [PubMed: 21713130]

121. Nakano T, Watanabe H, Homae F, Taga G. Pre-frontal cortical involvement in young infants' analysis of novelty. Cereb Cortex. 2009; 19:455-463. DOI: 10.1093/cercor/bhn096 [PubMed: 18544555]

122. Sato Y, Mori K, Furuya I, Hayashi R, Minagawa-Kawai Y, Koizumi T. Developmental changes in cerebral lateralization to spoken language in infants: measured by near-infrared spectroscopy. Jpn J Logoped Phoniatr. 2003; 44:165-171.

123. Sato Y, Sogabe Y, Mazuka R. Development of hemispheric specialization for lexical pitch-accent in Japanese infants. J Cogn Neurosci. 2009; 22:2503-2513. [PubMed: 19925204]

124. Minagawa-Kawai Y, Cristià A, Dupoux E. Cerebral lateralization and early speech acquisition: a developmental scenario. Dev Cogn Neurosci. 2011; 1:217-232. DOI: 10.1016/j.dcn.2011.03.005 [PubMed: 22436509]

125. Telkemeyer S, Rossi S, Koch SP, Nierhaus T, Steinbrink J, Poeppel D, Obrig H, Wartenburger I. Sensitivity of newborn auditory cortex to the temporal structure of sounds. J Neurosci. 2009; 29:14726-14733. DOI: 10.1523/jneurosci.1246-09.2009 [PubMed: 19940167]

126. Telkemeyer S, Rossi S, Nierhaus T, Steinbrink J, Obrig H, Wartenburger I. Acoustic processing of temporally modulated sounds in infants: evidence from a combined near-infrared spectroscopy and EEG study. Front Psychol. 2011; 2:1-14. DOI: 10.3389/fpsyg.2011.00062 [PubMed: 21713130]

127. Benavides-Varela S, Gomez DM, Mehler J. Studying neonates' language and memory capacities with functional near-infrared spectroscopy. Front Psychol. 2011; 2:1-5. DOI: 10.3389/fpsyg. 2011.00064 [PubMed: 21713130]

128. Benavides-Varela S, Hochmann J-R, Macagno F, Nespor M, Mehler J. Newborn's brain activity signals the origin of word memories. Proc Natl Acad Sci USA. 2012; 109:17908-17913. DOI: 10.1073/pnas.1205413109 [PubMed: 23071325]

129. Gomez DM, Berent I, Benavides-Varela S, Bion RAH, Cattarossi L, Nespor M, Mehler J. Language universals at birth. Proc Natl Acad Sci USA. 2014; 111:5837-5841. DOI: 10.1073/ pnas.1318261111 [PubMed: 24706790]

130. Bortfeld H, Fava E, Boas DA. Identifying cortical lateralization of speech processing in infants using near-infrared spectroscopy. Dev Neuropsychol. 2009; 34:52-65. DOI: 10.1080/87565640802564481 [PubMed: 19142766]

131. Kotilahti K, Nissila I, Nasi T, Lipiainen L, Noponen T, Merilainen P, Huotilainen M, Fellman V. Hemodynamic responses to speech and music in newborn infants. Hum Brain Mapp. 2010; 31:595-603. DOI: 10.1002/hbm.20890 [PubMed: 19790172]

132. Sato H, Hirabayaski Y, Tsubokura H, Kanai M, Ashida T, Konishi I, Uchida-Ota M, Konishi Y, Maki A. Cerebral hemodynamics in newborn infants exposed to speech sounds: a whole-head optical topography study. Hum Brain Mapp. 2012; 33:2092-2103. DOI: 10.1002/hbm.21350 [PubMed: 21714036]

133. Perani D, Saccuman MC, Scifo P, Anwander A, Spada D, Baldoli C, Poloniato A, Lohmann G, Friederici AD. Neural language networks at birth. Proc Natl Acad Sci USA. 2011; 108:1605616061. DOI: 10.1073/pnas.1102991108 [PubMed: 21896765]

134. Dehaene-Lambertz G, Dehaene S, Hertz-Pannier L. Functional neuroimaging of speech perception in infants. Science. 2002; 298:2013-2015. [PubMed: 12471265]

135. Dehaene-Lambertz G, Hertz-Pannier L, Dubois J, Meriaux S, Roche A, Sigman M, Dehaene S. Functional organization of perisylvian activation during presentation of sentences in preverbal 
infants. Proc Natl Acad Sci USA. 2006; 103:14240-14245. DOI: 10.1073/pnas.0606302103

[PubMed: 16968771]

136. Grossmann T, Oberecker R, Koch SP, Friederici AD. The developmental origins of voice processing in the human brain. Neuron. 2010; 65:852-858. DOI: 10.1016/j.neuron.2010.03.001 [PubMed: 20346760]

137. May L, Byers-Heinlein K, Gervain J, Werker JF. Language and the newborn brain: does prenatal language experience shape the neonate neural response to speech? Front Psychol. 2011; 2:1-9. DOI: 10.3389/fpsyg.2011.00222 [PubMed: 21713130]

138. Homae F, Watanabe H, Nakano T, Asakawa K, Taga G. The right hemisphere of sleeping infant perceives sentential prosody. Neurosci Res. 2006; 54:276-280. [PubMed: 16427714]

139. Homae F, Watanabe H, Nakano T, Taga G. Prosodic processing in the developing brain. Neurosci Res. 2007; 2007:29-39. [PubMed: 17590470]

140. Lloyd-Fox S, Blasi A, Mercure E, Elwell CE, Johnson MH. The emergence of cerebral specialization for the human voice over the first months of life. Soc Neurosci. 2012; 7:317-330. DOI: 10.1080/17470919.2011.614696 [PubMed: 21950945]

141. Minagawa-Kawai Y, van der Lely H, Ramus F, Sato Y, Mazuka R, Dupoux E. Optical brain imaging reveals general auditory and language-specific processing in early infant development. Cereb Cortex. 2011; 21:254-261. DOI: 10.1093/cercor/bhq082 [PubMed: 20497946]

142. Blasi A, Mercure E, Lloyd-Fox S, Thomson A, Brammer M, Sauter D, Deeley Q, Barker GJ, Renvall V, Deoni S, et al. Early specialization for voice and emotion processing in the infant brain. Curr Biol. 2011; 21:1220-1224. DOI: 10.1016/j.cub.2011.06.009 [PubMed: 21723130]

143. Gervain J, Berent I, Werker JF. Binding at birth: the newborn brain detects identity relations and sequential position in speech. J Cogn Neurosci. 2012; 24:564-574. [PubMed: 22066581]

144. Wagner JB, Fox SE, Tager-Flusberg H, Nelson CA. Neural processing of repetition and nonrepetition grammars in 7- and 9-month-old infants. Front Psychol. 2011; 2:1-8. DOI: 10.3389/ fpsyg.2011.00168 [PubMed: 21713130]

145. Homae F, Watanabe H, Otobe T, Nakano T, Go T, Konishi Y, Taga G. Development of global cortical networks in early infancy. J Neurosci. 2010; 30:4877-4882. [PubMed: 20371807]

146. Homae F, Watanabe H, Nakano T, Taga G. Large-scale brain networks underlying language acquisition in early infancy. Front Psychol. 2011; 2:1-14. DOI: 10.3389/fpsyg.2011.00093 [PubMed: 21713130]

147. Imai M, Watanabe H, Yasui K, Kimura Y, Shitara Y, Tsuchida S, Takahashi N, Taga G. Functional connectivity of the cortex of term and preterm infants and infants with Down's syndrome. Neuroimage. 2014; 85:272-278. DOI: 10.1016/j.neuroimage.2013.04.080 [PubMed: 23631984]

148. Scholkmann F, Holper L, Wolf U, Wolf M. A new methodical approach in neuroscience: assessing inter-personal brain coupling using functional near-infrared imaging (fNIRI) hyperscanning. Front Neurosci. 2013; 7:1-6. DOI: 10.3389/fnhum.2013.00813 [PubMed: 23386807]

149. Piper SK, Krueger A, Koch SP, Mehnert J, Habermehl C, Steinbrink J, Obrig H, Schmitz CH. A wearable multi-channel fNIRS system for brain imaging in freely moving subjects. Neuroimage. 2014; 85:64-71. DOI: 10.1016/j.neuroimage.2013.06.062 [PubMed: 23810973]

\section{FURTHER READING}

150. Boas DA, Elwell CE, Ferrari M, Taga G. Twenty years of functional near-infrared spectroscopy: introduction of the special issue. Neuroimage. 2014; 85:1-5. [PubMed: 24321364]

151. Aslin RN. Questioning the questions that have been asked about the infant brain using nearinfrared spectroscopy. Cogn Neuropsychol. 2012; 29:7-33. [PubMed: 22329690]

152. Meek J. Basic principles of optical imaging and application to the study of infant development. Dev Sci. 2002; 2002:371-380.

153. Ferrari M, Quaresima V. A brief review on the history of human functional near-infrared spectroscopy (fNIRS) development and fields of application. Neuroimage. 2012; 63:921-935. DOI: 10.1016/j.neuroimage.2012.03.049 [PubMed: 22510258]

Wiley Interdiscip Rev Cogn Sci. Author manuscript; available in PMC 2016 August 10. 


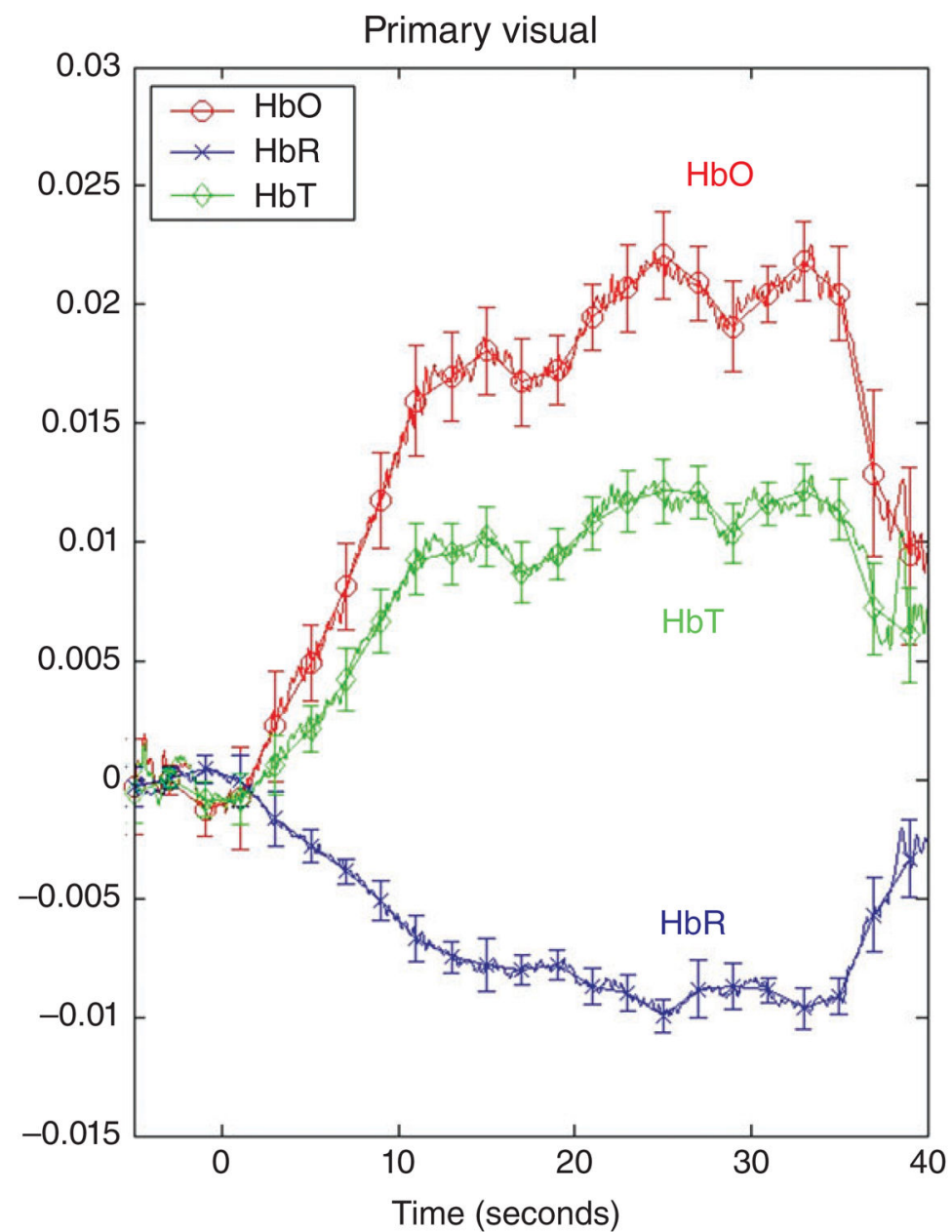

FIGURE 1.

Mean change in $\mathrm{HbO}, \mathrm{HbR}$, and $\mathrm{HbT}$ in the primary visual cortex in response to a visual event. (Reprinted with permission from Wilcox et al. ${ }^{40}$ ). The visual event was an occlusion sequence involving a green dotted ball and a red studded box. On the $y$-axis are relative optical density units and on the $x$-axis is time: -5 to 0 is the pre-stimulus baseline, 1-30 seconds is the visual event, and 31-40 seconds is the post-stimulus baseline. Relative changes in $\mathrm{HbO}, \mathrm{HbR}$, and $\mathrm{HbT}$, averaged over 10-30 seconds of the test trial, were compared to 0 . All responses $(\mathrm{HbO}, \mathrm{HbR}$, and $\mathrm{HbT})$ differed significantly from $0(P<.01)$ 


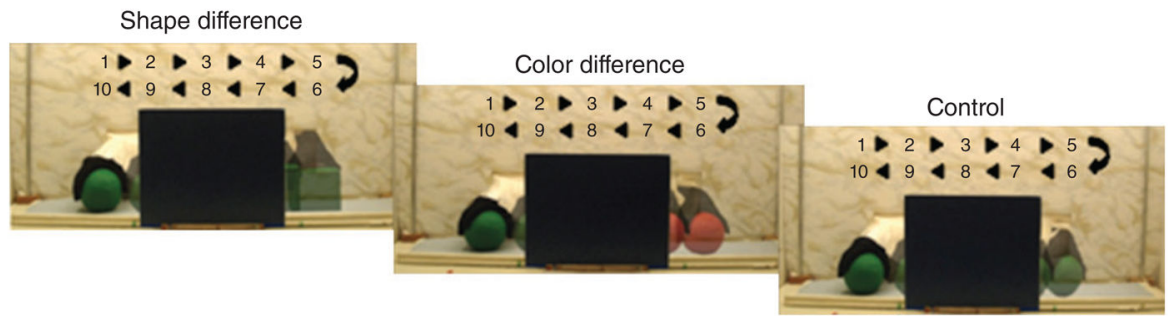

\section{FIGURE 2.}

The shape difference, color difference, and control test events of Wilcox et al. ${ }^{56}$ Each cycle of the test event was 10 seconds and infants saw two complete cycles during each test trial. These events were presented live in a puppet stage apparatus. During the baseline interval, a curtain was lowered over the opening of the apparatus and infants received no auditory or visual stimulation. 

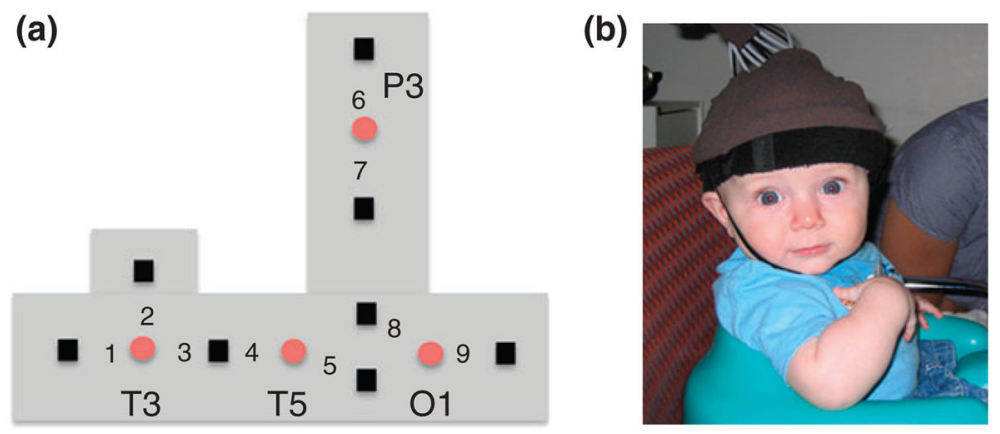

FIGURE 3.

The headgear used by Wilcox et al. ${ }^{56}$ (a) Configuration of the emitters (red circles) and detectors (black squares), and the nine measurement channels, in the headgear. Emitters were placed relative to 10-20 coordinates of the International 10-20 system (Figure 4). All the emitter-detector distances were $2 \mathrm{~cm}$. Each detector read from a single emitter except for the detector between T3 and T5, which read from both emitters. The light was frequency modulated to prevent 'cross-talk'. O1 lay over occipital cortex, T5 over posterior temporal cortex, T3 over anterior temporal cortex, and P3 over posterior parietal cortex. (b) Infants sat in a supportive seat to restrain excess movement. An elasticized headband was slid onto the infant's head and secured by a chinstrap. 

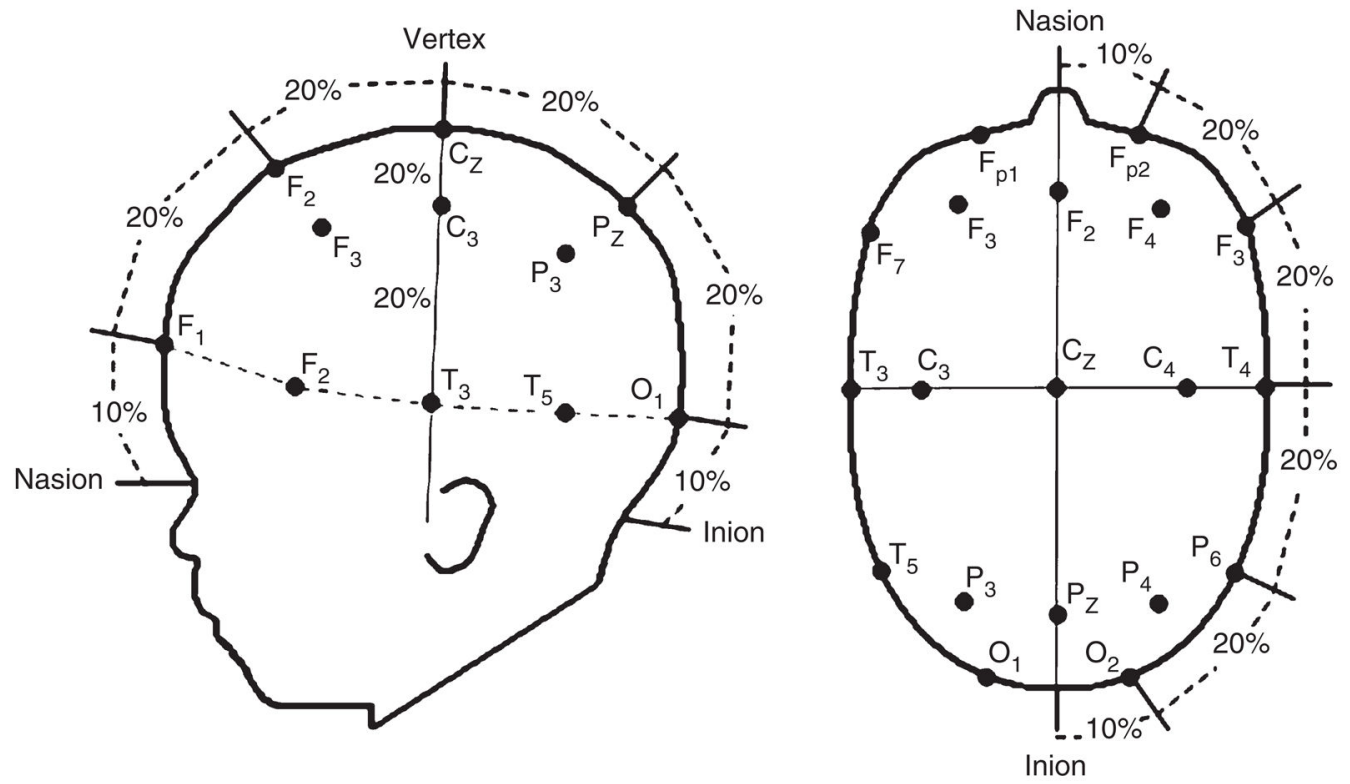

FIGURE 4.

The International 10-20 system for electrode placement projected onto a schematic of an infant's head. 


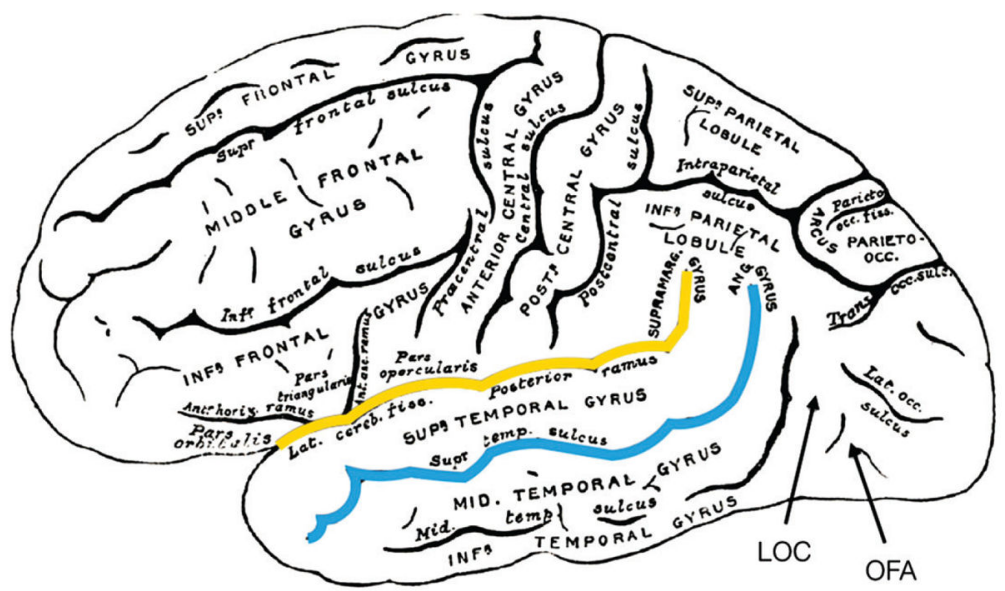

FIGURE 5.

Lateral view of the adult human brain (Greys Anatomy 726) with cortical areas labeled. Approximate locations of the lateral occipital complex (LOC) and occipital face area (OFA) are displayed. The fusiform face area (FFA) is located underneath the surface of the cortex, hence cannot be viewed here or investigated using fNIRS. The superior temporal sulcus is highlighted in red and the Sylvian fissure (or lateral sulcus) is highlighted in yellow. 


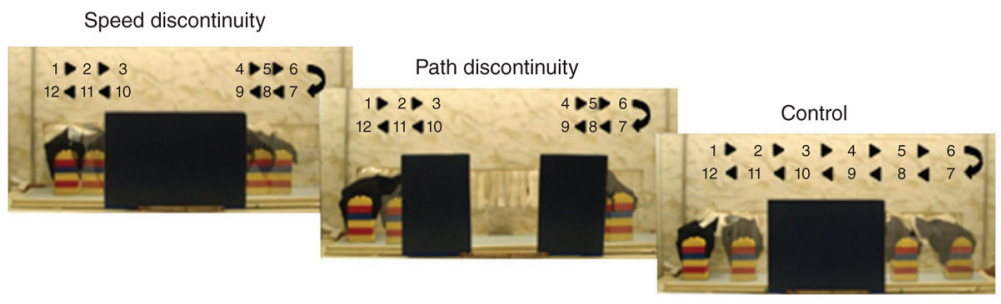

FIGURE 6.

The speed-discontinuity, path-discontinuity, and control test events of Wilcox et al. ${ }^{55}$ Each cycle of the test event was 12 seconds and infants saw two complete cycles during each test trial. These events were presented live in a puppet stage apparatus. During the baseline interval, a curtain was lowered over the opening of the apparatus and infants received no auditory or visual stimulation. 
(a)

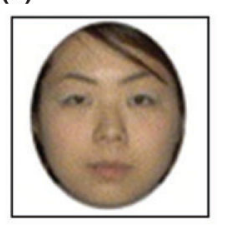

(b)

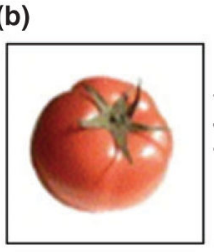

(d) (c)

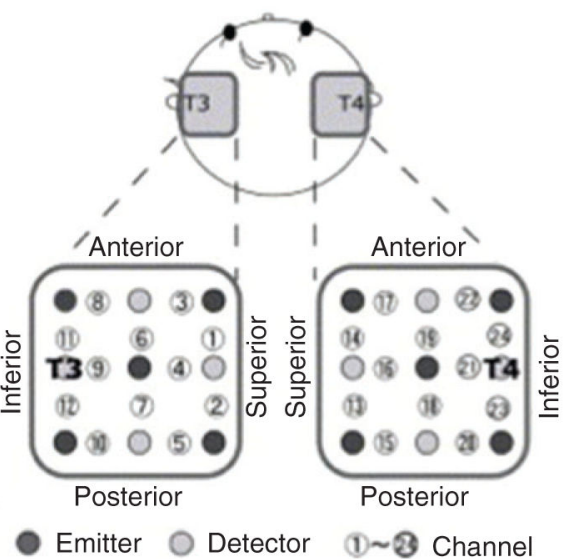

- Emitter $\bigcirc$ Detector (1) (3 Channel

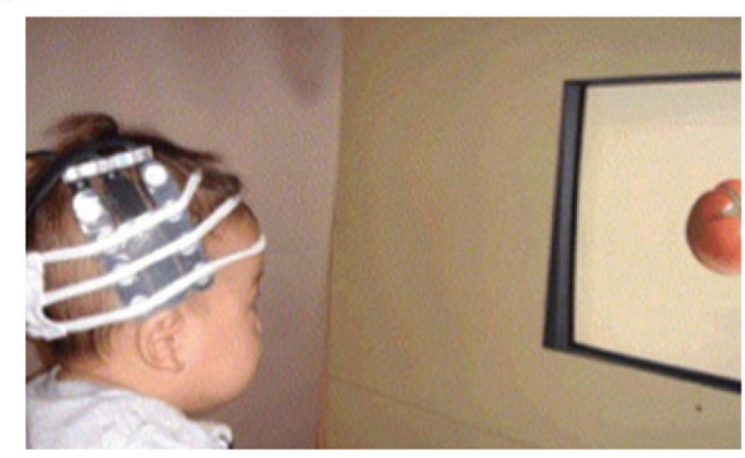

FIGURE 7.

Figure 1 ( $a$ and $b$ ) Examples of the face and object stimuli used by Otsuka et al. ${ }^{81}$ (c) Location of the optical fibers placed in each hemisphere. The distance between the fibers was $2 \mathrm{~cm}$. T3 and T4 were located at the center between channels 11 and 12 and 23 and 24, respectively. (d) An infant wearing the headgear during the experimental session. (Reprinted with permission from Ref 81. Copyright 2006 Elsevier) 
(a)
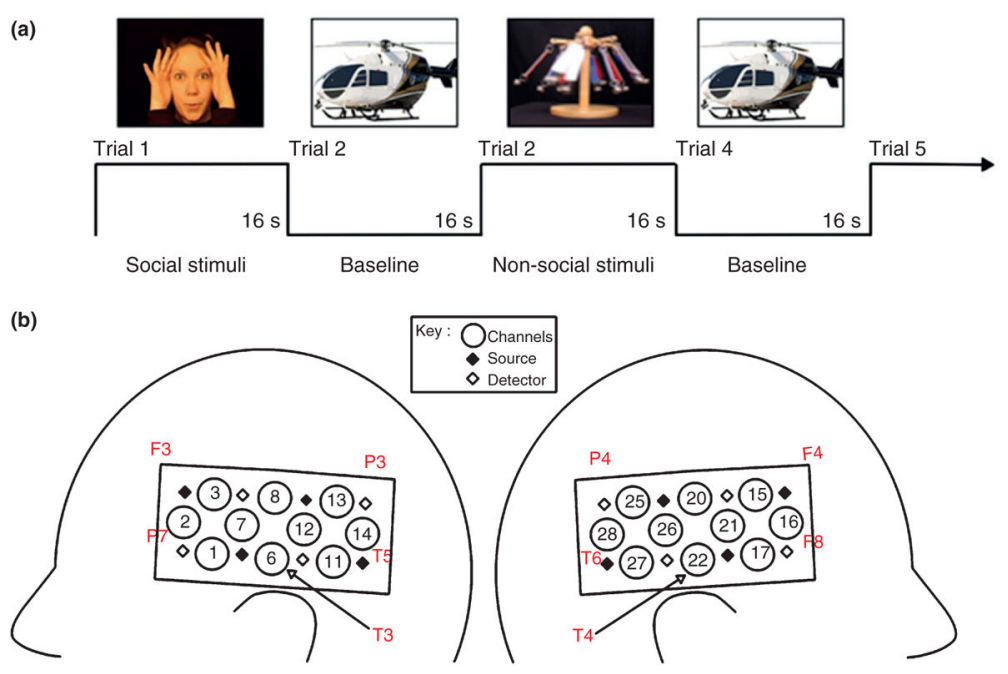

FIGURE 8.

(a) An example of the dynamic biological and mechanical test stimuli, and the static baseline stimuli, of Lloyd-Fox et al. ${ }^{37}$ (b) A schematic view of the headgear configuration with the approximate location of the channels shown in relation to the International 10-20 system. (Reprinted with permission from Ref 37. Copyright 2009 John Wiley \& Sons) 


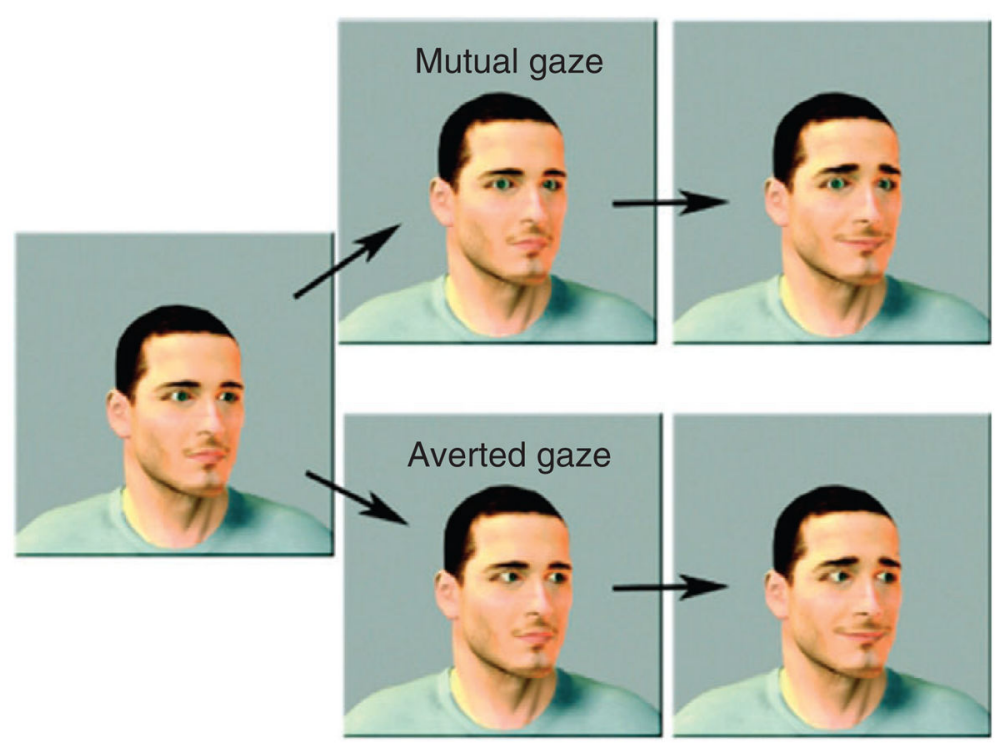

FIGURE 9.

Still frames from the dynamic face stimuli used by Grossman et al. ${ }^{41}$ Gender, age, and orientation of the face were randomly varied and counterbalanced. In the mutual gaze condition (upper half), the person's eyes moved toward the infant, and in the averted gaze condition (lower half), the person's eyes moved away from the infant. The eyebrow-raised and closed-mouth smiles were identical in the two conditions. (Reprinted with permission from Ref 41. Copyright 2008 Royal Society) 
(a)

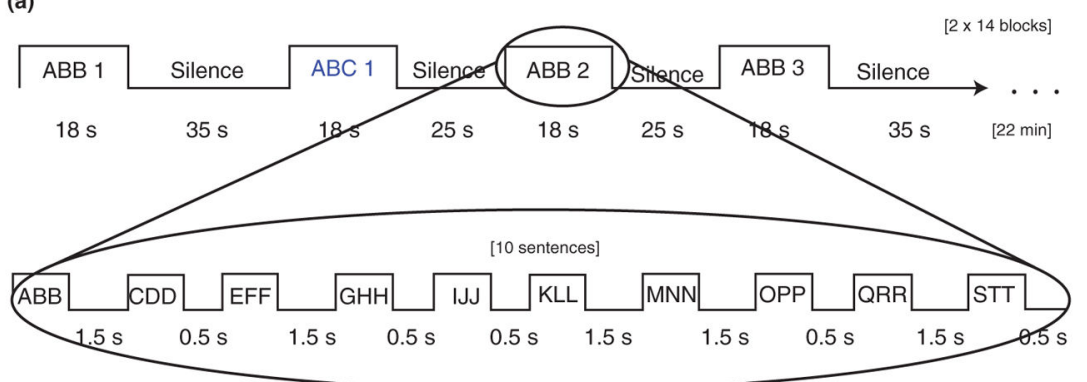

(b)

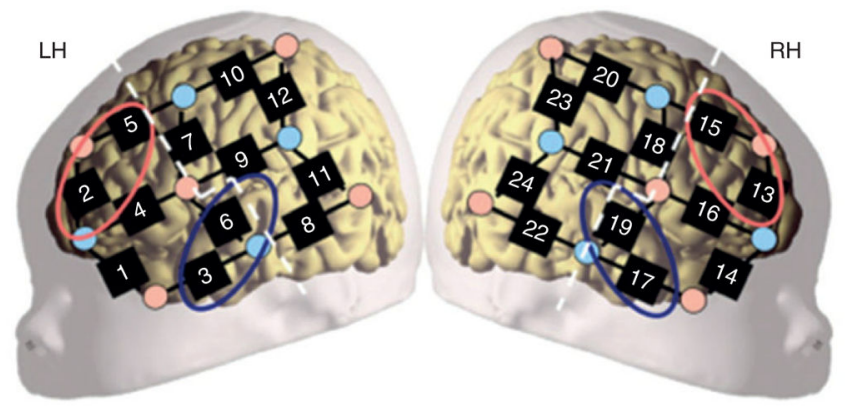

FIGURE 10.

Details of the procedure used by Gervain et al. ${ }^{10}$ (a) The experiments' design. The upper boxcar shows how the consecutive stimulation blocks unfold. The lower boxcar indicates the sequence of sentence types within a block. (b) The placement of the probes overlaid on a schematic neonate brain. Although individual variation cannot be excluded, this placement ensured recording from perisylvian and anterior brain regions. The dashed white lines separate anterior and posterior ROIs. The red ellipses indicate the channels included in the frontal area of interest (LH: channels 2 and 5; RH: channels 13 and 15). The blue ellipses indicate channels included in the temporal area of interest (LH: channels 3 and 6; RH: channels 17 and 19). (Reprinted with permission from Ref 10. Copyright 2008 National Academy of Sciences). 